\title{
A Design of a Hybrid Non-Linear Control Algorithm
}

\author{
Farinaz Behrooz 1,2,* (D), Norman Mariun 1,2, Mohammad Hamiruce Marhaban ${ }^{1}$, \\ Mohd Amran Mohd Radzi ${ }^{1}$ id and Abdul Rahman Ramli ${ }^{3}$ \\ 1 Department of Electrical and Electronic Engineering, Faculty of Engineering, Universiti Putra Malaysia, \\ Serdang 43400, Selangor, Malaysia; norman@upm.edu.my (N.M.); hamiruce@upm.edu.my (M.H.M.); \\ amranmr@upm.edu.my (M.A.M.R.) \\ 2 Centre for Advanced Power and Energy Research, Faculty of Engineering, University Putra Malaysia, \\ Serdang 43400, Selangor, Malaysia \\ 3 Department of Computer and Communication Engineering, Faculty of Engineering, \\ Universiti Putra Malaysia, Serdang 43400, Selangor, Malaysia; arr@upm.edu.my \\ * Correspondence: fery_behrooz@yahoo.com; Tel.: +60-11-2385-6710
}

Received: 3 September 2017; Accepted: 17 October 2017; Published: 10 November 2017

\begin{abstract}
One of the high energy consuming devices in the buildings is the air-conditioning system. Designing a proper controller to consider the thermal comfort and simultaneously control the energy usage of the device will impact on the system energy efficiency and its performance. The aim of this study was to design a Multiple-Input and Multiple-Output (MIMO), non-linear, and intelligent controller on direct expansion air-conditioning system The control algorithm uses the Fuzzy Cognitive Map method as a main controller and the Generalized Predictive Control method is used for assigning the initial weights of the main controller. The results of the proposed controller shows that the controller was successfully designed and works in set point tracking and under disturbance rejection tests. The obtained results of the Generalized Predictive Control-Fuzzy Cognitive Map controller are compared with the previous MIMO Linear Quadratic Gaussian control design on the same direct expansion air-conditioning system under the same conditions. The comparative results indicate energy savings would be achieved with the proposed controller with long-term usage. Energy efficiency and thermal comfort conditions are achieved by the proposed controller.
\end{abstract}

Keywords: Generalized Predictive Control; Fuzzy Cognitive Map; direct expansion air-conditioning system; non-linear system; MIMO system; energy efficiency

\section{Introduction}

Due to their high energy consumption and the high demand for installation of these devices in the buildings, nowadays different controllers are applied in heating, ventilating and air-conditioning systems (HVACs) to improve the system performance. The most significant considerations when designing HVAC systems are the indoor thermal conditions and energy efficiency [1]. The complicated features of HVAC systems make mathematical modelling of systems very difficult or sometimes impossible [1]. Therefore, the design of proper controllers for HVAC systems has become a great challenge [2,3]. As the HVAC systems use high amounts of energy, even small improvements in the system operational efficiency can result in significant energy savings [4]. Hence, many studies have been done in the control of HVAC and A/C systems and the optimization area.

Providing thermal comfort is the main and most important purpose of designing the HVAC, and $\mathrm{A} / \mathrm{C}$ systems in buildings. Therefore, advanced control methods are needed to consider the $\mathrm{MIMO}$, nonlinearity, coupling effect of the parameters and complex features of the system, while at the same time considering the occupant's thermal comfort demand and the system's energy efficiency. Hence, MIMO, nonlinear, intelligent and robust controllers are desired to achieve the mentioned 
aims simultaneously. Accordingly, the intelligent base soft computing control scenario is required to consider the nonlinearity and MIMO structure of the system.

As one of the most important concerns of control engineers is to mimic reality as close as possible and also for the designed system to be practically applicable, designing advance control techniques by taking into account the characteristics of the system is required. As the purpose of this work is to control a direct expansion air conditioning (DX A/C) system, the MIMO, coupled parameters, and nonlinearity structure of the system should be considered in any control algorithm.

As the structures of HVAC systems are complex and uncertain, the application of nonlinear control methods has limitations. The most important reasons among others are the complex mathematical analysis, stability analysis and dependence on a whole set of states [5]. The air-handling unit (AHU) was controlled separately by gain scheduling and feedback linearization methods [6]. Both methods were applied on a non-linear MIMO dynamic model of an AHU in which the air flow rates and cold water are used for achieving to the desired indoor temperature and humidity. Controlling the system by using the feedback linearization method, the tracking objectives of temperature and humidity ratio are very quick, but the results show more overshoots. By applying the gain scheduling controller on an AHU, less energy consumption was achieved. In order to track the objectives, less variation of air and cold water flow rates are required. In contrast, by using a gain scheduling method, the identification of linear regions and design of switching logic between regions is essential. PID controllers are used as switching logic between regions and their manual tuning can be quite cumbersome. A non-linear adaptive back-stepping control algorithm was used to control multi-variable nonlinear mathematical model HVAC systems [7]. The Lyapunov stability is used in this method. Energy management of the system is achieved by using this energy efficient controller, therefore, this control method has been utilized in the field of intelligent building energy saving. The disadvantages of this method are the need for a bilinear observer, and the difficulty in finding Lyapunov stability. A back-stepping controller on the feedback linearized model of the single-zone VAV HVAC \& R system was applied by Qi [8]. A bilinear model was used to describe the temperature and humidity dynamics. The heat and moisture loads were considered as measurable disturbances. The back-stepping controller was used on the feedback linearized model in order to design a stable observer for non-measurable disturbances backed by simulation results to attain the optimal energy consumption. The simulation results of the closed-loop system indicate good and fast tracking, offset-free and smooth response with high disturbance decoupling and optimal energy consumption properties in the presence of time-varying loads. Due to the difficulty in finding a Lyapunov function, all state variables must be measurable; otherwise, the need for a non-linear observer is one of the shortcomings of this method. In other words, the complex mathematic analysis, and the need to design the linearization controller and decouple the model to find some required parameters, using others method to transform the linearized model into a non-linear form are the main disadvantages of this control design. A Non-Linear Optimal Controller for HVAC systems was designed based on input/output feedback linearization, a MATLAB/Simulink response optimizer and non-linear programming by Dong [9]. By designing the non-linear optimal controller, energy savings are obtained. The main contribution of this control method is the development of sustainable and energy efficient buildings. Additional parameters are however required in this method, which makes the integration in real HVAC systems difficult and impractical. Hence, the application of non-linear control methods like feedback linearization, gain scheduling, and back-stepping controllers presents some disadvantages such as overshoots, identification of linear regions, design of switching logic between regions, difficulty in finding a Lyapunov function, linearization and decoupling the model to find some required parameters, by using another method to transfer the model to the non-linear form.

HVAC and A/C systems are basically MIMO systems. Nevertheless, sometimes for making the control design easy, they are considered as SISO systems when designing a controller [3]. It is clear that the performance of MIMO control strategies is inherently better than conventional SISO control strategies. In addition, due to the coupling effect between parameters, especially in the DX 
A/C structure, MIMO control strategies are required to consider the coupling effects of variables. Online auto-tuned Takagi-Sugeno Fuzzy Forward control is used on the non-linear model of HVAC systems by using predicted mean vote index (PMV) as an objective instead of temperature and relative humidity. This method is able to solve the coupling effect of temperature and humidity. The accuracy and efficiency by optimizing between the temperature and relative humidity are achieved by using PMV as a reference. Nonetheless, the implementation of fuzzy logic control requires comprehensive knowledge of the plant operation and its different states. The GPC method was applied for tuning the PID controller parameters by $\mathrm{Xu}$ et al. [10], as well as $\mathrm{Xu}$ and Li [11] which used the GPC method to decouple a HVAC \& R system together with parameter identification. In comparison to the coupled system, this method requires less computation.

In the HVAC area MIMO control strategies are mostly applied to the linearized model of the system around the operating point. This means that the controller works in a limited range. The MIMO Linear Quadratic Gaussian (LQG) control method was applied on a DX A/C system by Qi [6]. The linearized model of the DX A/C system is used at the system's operating point, meaning that the designed controller is not suitable for non-linear conditions and it only works and is stable around that operating point. The controller is not implemented for a wider operating range. The controller results are in the range of $24{ }^{\circ} \mathrm{C}$ for temperature and $50 \%$ for humidity, and the controller does not have the ability to decrease the temperature from more than $25{ }^{\circ} \mathrm{C}$ and humidity from more than $60 \%$. A linear predictive control concept for a solar powered HVAC system was used by Ferhatbegovíc et al. [12]. Dynamic models of the HVAC components were used for designing the controller and validated by carried out measurements on a real HVAC system. By using weather forecast information, the MPC performance indicates excellent performance, even when the incorrect information is provided by a weather forecast. The receding horizon strategy of the MPC concept strictly accounts for such cases where the predicted information is not correct. Thus, a non-linear model predictive controller is required.

As the purpose of this study is to control a DX A/C system, the problem when designing a suitable controller is how to hold the features of the system unchanged which have a MIMO structure, the coupling effect between parameters and non-linearity by designing a simple structure and easy implementation controller. In other words, which method is suitable for designing the controller in which the structure of the system is considered as non-linear MIMO with coupling effects and at the same time this controller should be practically applicable. In order to solve this problem, the chosen method for designing the controller is based on a Fuzzy Cognitive Map. Due to the specific structure of this method, the MIMO structure and coupling effect can be consider as a graph structure network by choosing the inputs and outputs of the system as nodes for the graph and the coupling effect between parameters can be shown and considered as a relationship between concepts and considering their effects on each other. The value of the parameters are applied on the non-linear model of the system and the non-linearity is also considered by this structure.

\section{Methodology}

The methodology flow chart of this work is illustrated in Figure 1. This flow chart is based on the methodology of this work in order to design a proper controller for the DX A/C system. In addition, it includes a stability analysis test of the proposed controller and its performance analysis by set point tracking, and disturbance rejection. Finally, a comparison between the mentioned controller and the Qi [8] work has been done under the same conditions for both controllers.

In order to control the DX A/C system, a control algorithm is required by considering the MIMO, non-linearity and coupling effect features of the system. Due to the structure of the GPC-FCM method for controlling the DX A/C system, the important characteristics of the system are considered. This intelligent MIMO nonlinear control algorithm is the main contribution of this study. By applying this control algorithm, the non-linear controller is designed without involving a difficult mathematic analysis for deriving the control law process. Better performance and energy savings are obtained 
by using the proposed controller in comparison with the previous applied controller on the same DX A/C system.

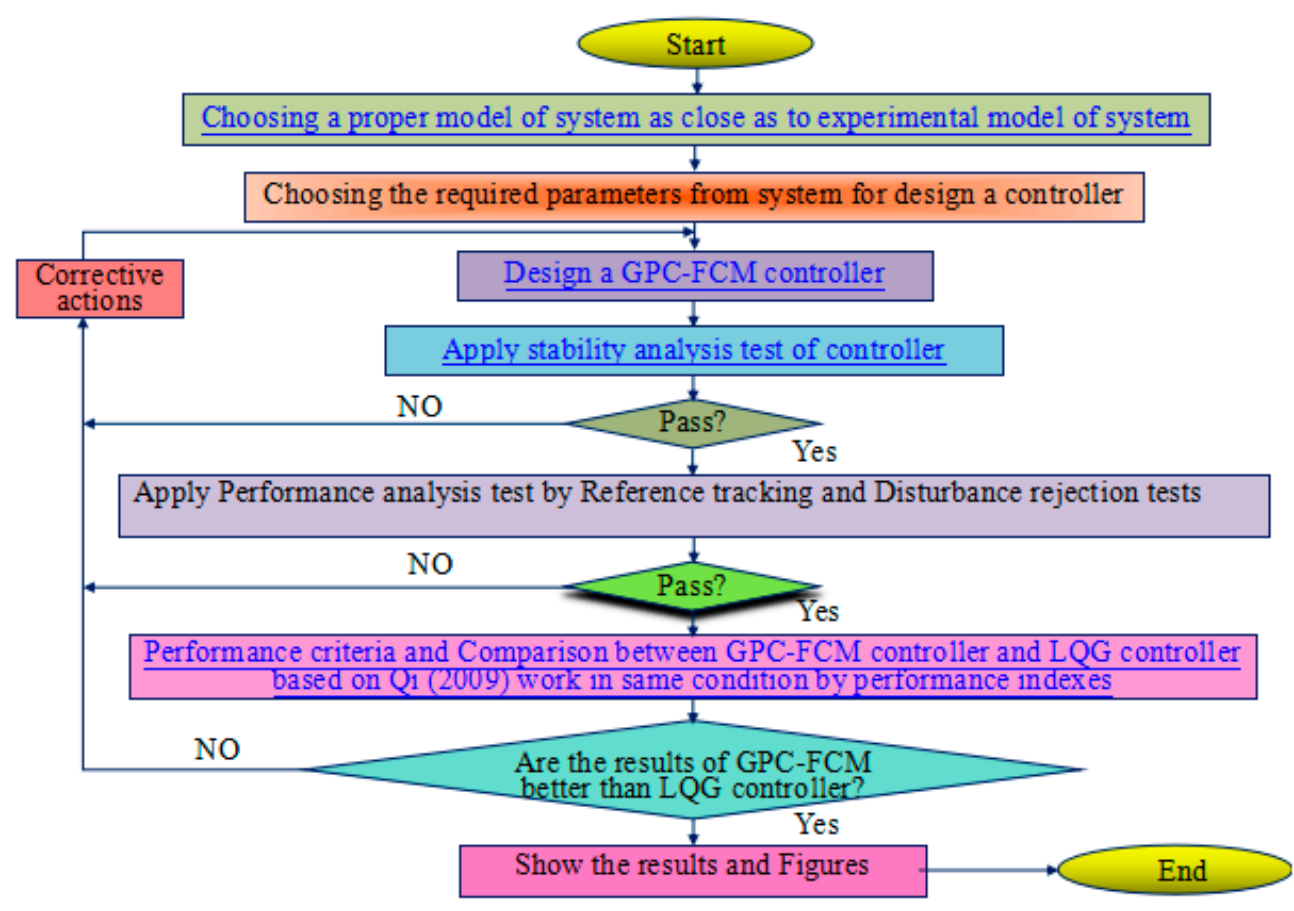

Figure 1. Flow chart of the methodology of the work.

\subsection{Choosing a Proper Model of the System}

The model of the DX A/C system in this research was adopted from Qi's [8] work. In order to mimic the conditions as closely as possible to the real conditions, the model offered by Qi [8] is chosen as an experimental model of the system, due to the experimental validation of the simulation model. The equation which was offered as an experimental model of the system are accurate enough to mimic the real conditions. This model is experimentally validated and established as a multivariable control-oriented modeling of a direct expansion air conditioning system. In other words, this model which is explained completely and comprehensively in the following sections, is almost practically same as the experimental behavior of the DX A/C system [6,8,13-15].

The construction of DX A/C system is divided into two parts: the air distribution part (air-conditioned room, supply fan, and ductwork) and the refrigeration part (evaporator, compressor, condenser, expansion valve, receiver, and oil separator) $[16,17]$. The desired set points for the air-conditioned room are provided by changing the speed of the compressor and the flow rate of the fan. Figure 2 shows the structure of a direct expansion air conditioning system with a variable speed compressor and supply fan. The structure of the DX A/C system and the dynamic mathematical model of the system is based on several works $[6,8,13,15,18]$. The required equations of the system which are achieved by using the principle of energy balance are described as follows $[6,8,13-17,19]$ :

$$
\begin{gathered}
C_{p} \rho V\left(\frac{d T R}{d t}\right)=C_{p} \rho f(S T-T R)+Q_{s p l}+Q_{\text {load }} \\
\rho V\left(\frac{d H R}{d t}\right)=\rho f(S H-H R)+M \\
\left(C_{p} \rho V\right)_{w}\left(\frac{d T_{w}}{d t}\right)=\alpha_{1} A_{1}\left(\left(\frac{T R+T_{3}}{2}\right)-T_{w}\right)+\alpha_{2} A_{2}\left(\left(\frac{T_{3}+S T}{2}\right)-T_{w}\right)-\frac{\left(s V_{c o m}\right)}{v_{s}\left(\frac{P_{c}}{P_{e}}\right)^{\frac{1}{\beta}}}\left(h_{r 2}-h_{r 1}\right)
\end{gathered}
$$




$$
\begin{gathered}
C_{p} \rho V_{h 2}\left(\frac{d S T}{d t}\right)+\rho V_{h 2} h_{f g h}\left(\frac{d S H}{d t}\right)=C_{p} \rho f\left(T_{3}-S T\right)+\rho f h_{f g h}(H R-S H)+\alpha_{2} A_{2}\left(T_{w}-\frac{\left(T_{3}+S T\right)}{2}\right) \\
\left(\frac{d S H}{d t}\right)-(2 \times 0.0198 S T+0.085)\left(\frac{d S T}{d t}\right)=0 \\
C_{p} \rho V_{h 1}\left(\frac{d T_{3}}{d t}\right)=C_{p} \rho f\left(T R-T_{3}\right)+\alpha_{1} A_{1}\left(T_{w}-\left(\frac{\left(T R+T_{3}\right)}{2}\right)\right)
\end{gathered}
$$

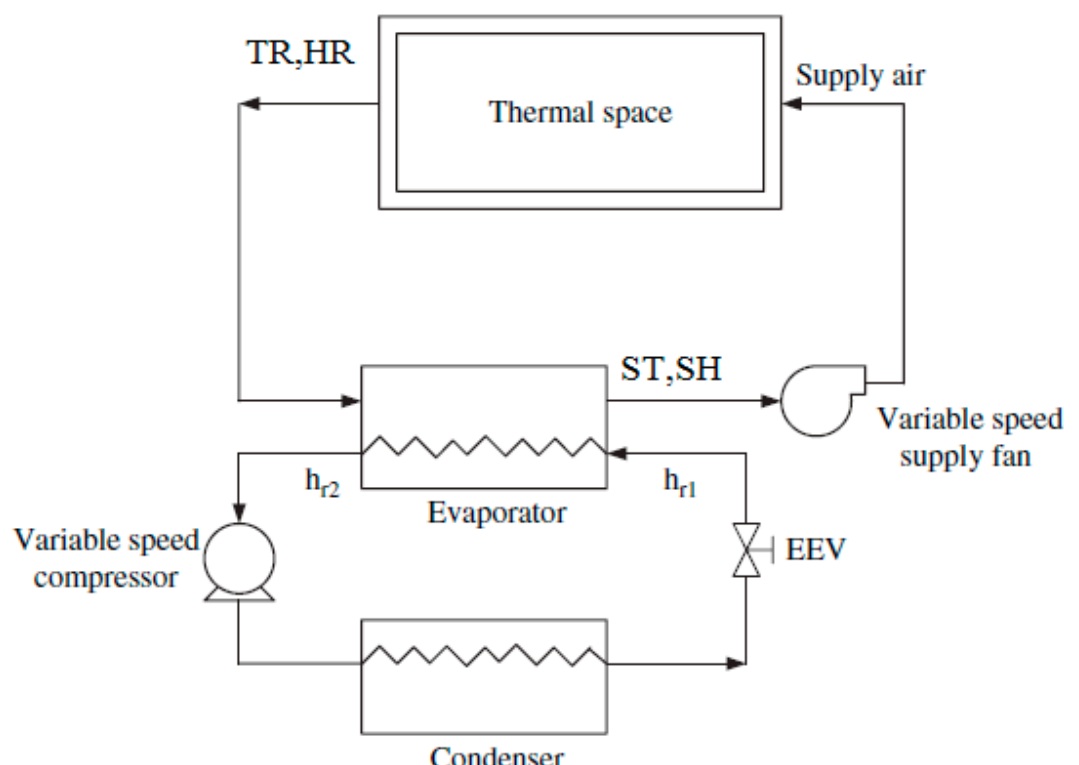

Figure 2. The structure of a direct expansion air conditioning system.

Table 1 lists the DX A/C system's parameters and their descriptions.

Table 1. Parameters of the system and their descriptions.

\begin{tabular}{cc}
\hline Parameter & Description \\
\hline$f$ & Volume of the air flow rate \\
$T_{w}$ & Evaporator tube wall's temperature \\
$A_{1}$ & Air side heat transfer area in dry-cooling region of evaporator \\
$V_{h 1}$ & Air side volume in dry-cooling region of evaporator \\
$S T$ & Supplied air temperature \\
$S H$ & Supplied humidity \\
$V_{h 2}$ & Volume of the wet-cooling region \\
$A_{2}$ & Area of the wet-cooling region in air side \\
$h_{f g h}$ & Vaporization of water's latent heat \\
$\beta$ & Compression index \\
$P_{c}$ & Condensing pressure \\
$P_{e}$ & Evaporating pressure \\
$S$ & Compressor speed \\
$v_{S}$ & Specific volume of superheated refrigerant \\
$T R$ & Air temperature \\
$H R$ & Air Humidity \\
$V$ & Solume of the air-conditioned space \\
$Q_{l o a d}$ & Heat gain of the supply fan \\
$Q_{s p l}$ & Reduced air temperature at the ending of the dry-cooling region in the evaporator \\
$M$ & Moisture load generation in the conditioned space. \\
$T_{3}$ & Convective heat transfer coefficients of evaporator airside in dry-cooling and Wet-cooling region \\
$\alpha_{1}, \alpha_{2}$ & Saturated refrigerant specific heat \\
$C_{p}$ &
\end{tabular}

Table 2 lists the numerical values and operating point of the DX A/C system based on [8]. 
Table 2. Numerical values and operating condition of the system.

\begin{tabular}{ccc}
\hline Variable & Value & Description \\
\hline$S T$ & $13.25^{\circ} \mathrm{C}$ & Supplied temperature \\
$R T$ & $24^{\circ} \mathrm{C}$ & Air-conditioned room temperature \\
$T_{3}$ & $17^{\circ} \mathrm{C}$ & Temperature at the end of the dry-cooling region \\
$T_{w}$ & $13{ }^{\circ} \mathrm{C}$ & Evaporator wall temperature \\
$A_{1}$ & $4.14 \mathrm{~m}^{2}$ & Air side heat transfer area of evaporator in dry-cooling region \\
$A_{2}$ & $17.65 \mathrm{~m}^{2}$ & Air side heat transfer area of evaporator in wet-cooling region \\
$S H$ & $9.03 \mathrm{~g} / \mathrm{kg} \mathrm{dry}$ air & Supplied humidity \\
$H R$ & $11.35 \mathrm{~g} / \mathrm{kg} \mathrm{dry} \mathrm{air}$ & Air-conditioned room humidity \\
$p_{c}$ & $1.812 \times 10^{6} \mathrm{pa}$ & Condensing pressure \\
$p_{e}$ & $0.486 \times 10^{6} \mathrm{pa}$ & Evaporating pressure \\
$M$ & $0.96 \mathrm{Kg} / \mathrm{s}$ & Specific heat \\
$C_{p}$ & $1.005 \mathrm{Kj} / \mathrm{kg}$ & Moisture load generation in the conditioned space \\
$\rho$ & $1.2 \mathrm{~kg} / \mathrm{m}^{3}$ & Air density at standard conditions \\
$Q_{l o a d}$ & $4.49 \mathrm{kw}$ & Space sensible load \\
$S$ & $3960 \mathrm{rpm}$ & Compressor speed \\
$f$ & $0.347 \mathrm{~m}^{3} / \mathrm{s}$ & Air volumetric flow rate \\
$V$ & $77 \mathrm{~m} 3$ & Volume of the conditioned space \\
$h_{f g h}$ & $2450 \mathrm{kj} / \mathrm{kg}$ & Latent heat of vaporization of water \\
\hline
\end{tabular}

With the purpose of designing the MIMO non-linear controller of the DX A/C system, all the above differential equations should be rewritten in the state-space format. Consequently, the state-space form of the DX A/C system model can be expressed in the following compact format $[6,8,13]$ :

$$
\dot{X}=D^{-1} \cdot g_{1}(X, U)+D^{-1} \cdot g_{2}(Z)
$$

$X=\left[S T, T R, T_{3}, T_{w}, S H, H R\right]$ is the state vector. $U=[f ; s]$ is the control input and $Z=[Q l o a d, M]$ is the disturbance. $g_{1}, g_{2}$ are the functions described as follows:

$$
\begin{aligned}
& g_{1}(X, U)=\left[\begin{array}{c}
C_{p} \rho f\left(T_{3}-S T\right)+\rho f h_{f g h}(H R-S H)+\alpha_{2} A_{2}\left(T_{w}-\frac{\left(T_{3}+S T\right)}{2}\right) \\
C_{p} \rho f(S T-T R)+Q_{s p l} \\
C_{p} \rho f\left(T R-T_{3}\right)+\alpha_{1} A_{1}\left(T_{w}-\left(\frac{\left(T R+T_{3}\right)}{2}\right)\right) \\
\alpha_{1} A_{1}\left(\left(\frac{T R+T_{3}}{2}\right)-T_{w}\right)+\alpha_{2} A_{2}\left(\left(\frac{T_{3}+S T}{2}\right)-T_{w}\right)-\frac{\left(s V_{c o m}\right)}{v_{s}\left(\frac{P_{c}}{P_{e}}\right)^{\frac{1}{\beta}}}\left(h_{r 2}-h_{r 1}\right) \\
0 \\
\rho f(S H-H R)
\end{array}\right] \\
& g_{2}(Z)=\left[\begin{array}{c}
0 \\
Q_{\text {load }} \\
0 \\
0 \\
0 \\
M
\end{array}\right] \\
& D=\left[\begin{array}{cccccc}
C_{p} \rho V_{h 2} & 0 & 0 & 0 & \rho V_{h 2} h_{f g h} & 0 \\
0 & C_{p} \rho V & 0 & 0 & 0 & 0 \\
0 & 0 & C_{p} \rho V_{h 1} & 0 & 0 & 0 \\
0 & 0 & 0 & \left(C_{p} \rho V\right)_{w} & 0 & 0 \\
\frac{-(2 \times 0.0198 S T+0.085)}{1000} & 0 & 0 & 0 & 1 & 0 \\
0 & 0 & 0 & 0 & 0 & \rho V
\end{array}\right]
\end{aligned}
$$




\subsection{Choosing the Required Parameters from the System for Designing a Controller}

Based on the control scenario algorithm for controlling the DX A/C system, the essential parameters selected as concepts of the controller are the following:

1. The air-conditioned room temperature (outputs).

2. The air-conditioned room humidity (outputs).

3. Supplied temperature (inputs).

4. Supplied humidity (inputs).

5. Speed of compressor (control signals).

6. Supply fan's flow rate (control signals).

\subsection{Designing the Proposed Controller}

A DX A/C system is a non-linear, inherently complex and MIMO system with coupling effects on supplied temperature and supplied humidity. It needs to control the air humidity and air temperature of the air-conditioned room at the same time by taking into account the coupling effect on exiting air humidity and temperature from the evaporator (supply air humidity and temperature), while also decreasing the energy usage of the system. Hence, a fast, robust, closed-loop and inherently simple control algorithm is required to achieve the desired temperature and humidity.

The chosen method for controlling the DX A/C system is a hybrid Generalized Predictive Control-Fuzzy Cognitive Map (GPC-FCM) controller. The core controller in this design is based on the FCM structure. The inputs and outputs of the system could be easily defined by the FCM method as nodes based on the control requirements of the system and the expected system performance scenario. In addition, the control variables are considered as effective parameters of the system. Since by changing the fan's flow rate and the speed of the compressor, control of the system is achieved, then these two parameters should be considered in the control design. Thus, the MIMO approach could be used without the linearization of the system. The other positive point of this structure is the causal relationship between the concepts in which the coupling effect between concepts could be considered as two side relationship of coupled parameters.

In order to assign suitable weights between the nodes of the FCM structure, the GPC method is used to find the minimum required values for the fan's flow rate and speed of the compressor. By combination of these two methods as a core controller and weight assigning controller, the hybrid method based on FCM and GPC methods is established. Figure 3 shows the block diagram of the closed loop system.

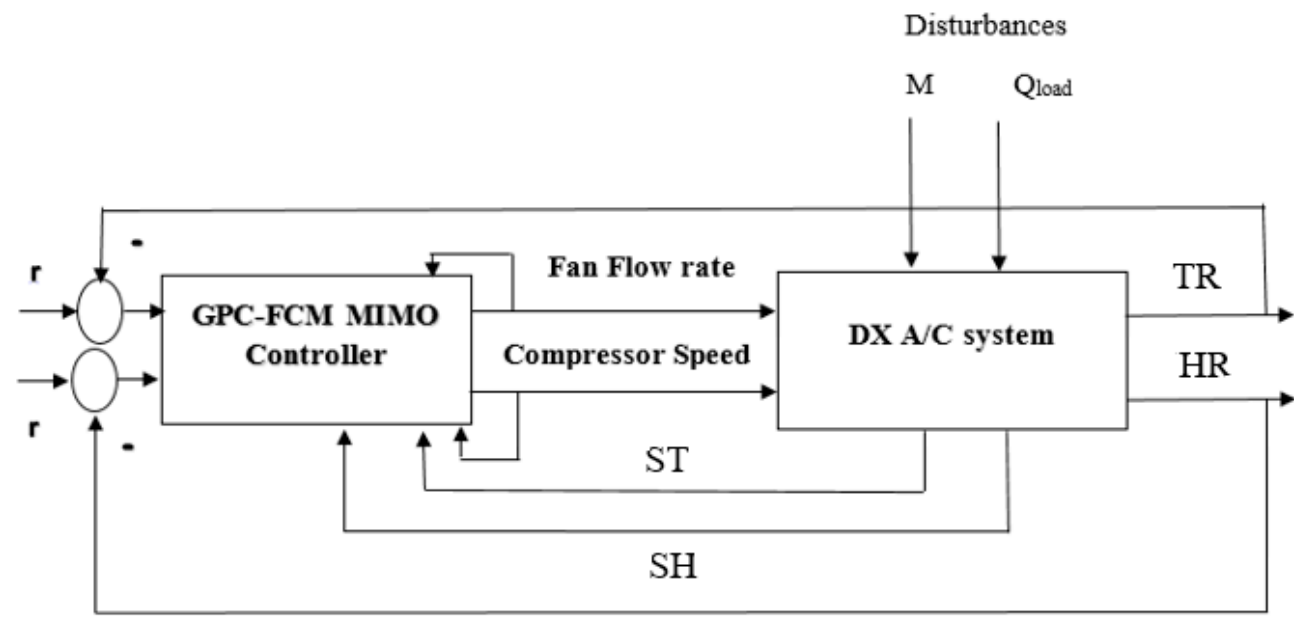

Figure 3. Block diagram of the closed loop system. 
The FCM control algorithm step by step is as follows:

(1) Identification of the correct and required concepts from the system, like inputs and outputs and any affecting parameters on the system as concepts and assigning the initial weights between the concepts based on GPC method.

(2) Fuzzification of the concept values $[20,21]$ by transformation mechanism.

(3) The weight matrix are adjusted by the differences within the concept values and their desired values $[22,23]$.

(4) The next step values of the controller are calculated by Equations (12) and (13).

(5) The required values of the concepts are defuzzified and applied to the actuators.

Figure 4 shows the control design flow chart.

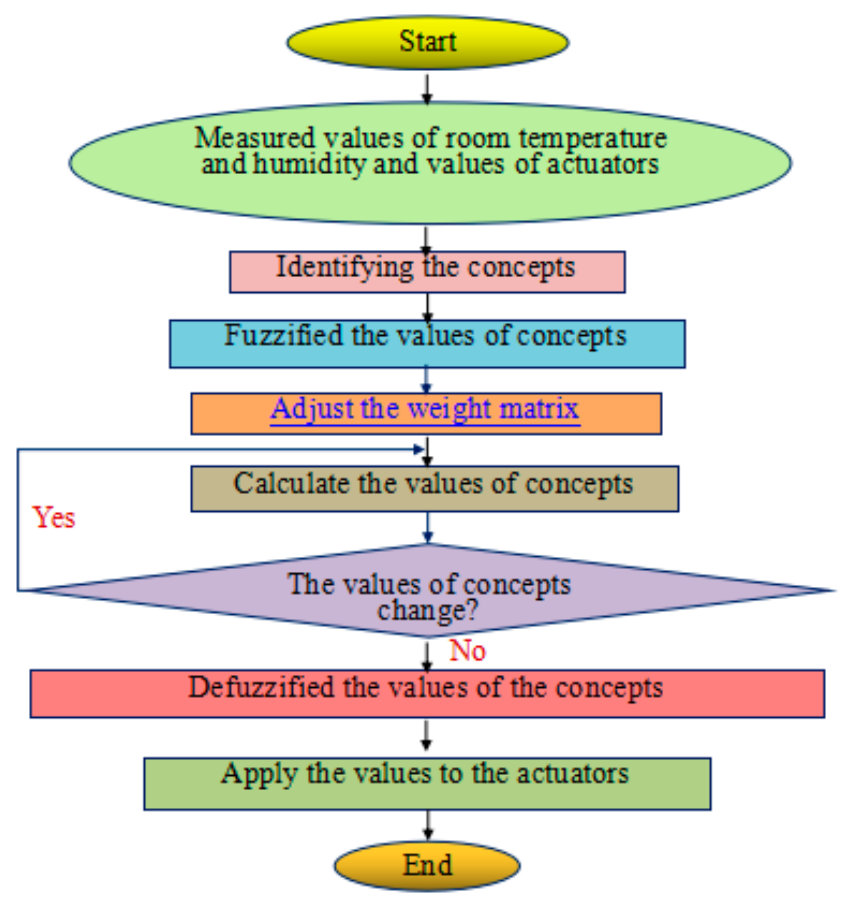

Figure 4. Flow chart of the controller.

2.3.1. Measuring the Values of the Room Temperature and Humidity and Values of the Actuators

The values of the air-conditioned room and air-conditioned humidity are calculated based on Equations (1) and (2). Also, the values of the supply air temperature and supply humidity are calculated based on Equations (4) and (5). The values of actuators are calculated based on the FCM mathematics which are explained in the section on calculation of the concept values. All of the calculated values are assumed to be the same as the measured ones.

\subsubsection{Identifying the Concepts}

In this design, six important parameters from the system are identified for designing the controller. The concepts for DX A/C model should be described as follows:

A1: Temperature of the room (TR),

A2: Humidity of the room (HR),

A3: Supply temperature (ST),

A4: Supply humidity (SH),

A5: Compressor speed (CS), and

A6: Flow rate of fan (FF) [24]. 


\subsubsection{Fuzzification of the Values of the Concepts}

Based on the FCM's structure, the real measured values of the concepts should be transformed to the interval $[0,1]$. By using the transformation mechanism, the real values of concepts are shifted to their fuzzy values. The selected transformation mechanism is [24]:

$$
g\left(s_{i}^{t}\right)=\left\{\begin{array}{cc}
0, & \text { if } s_{i}^{t} \leq a_{i} \\
\frac{s_{i}^{t}-a_{i}}{\left[2\left(m_{i}-a_{i}\right)\right]}, & \text { if } a_{i} \leq s_{i}^{t} \leq m_{i} \\
0.5+\frac{s_{i}^{t}-m_{i}}{\left[2\left(b_{i}-m_{i}\right)\right]}, & \text { if } m_{i} \leq s_{i}^{t} \leq b_{i} \\
1, & \text { if } s_{i}^{t}>b_{i}
\end{array}\right.
$$

where $s_{i}{ }^{t}$ is the measured value of the $i_{\text {th }}$ state at time $t, a_{i}$ is $\min , m_{i}$ is average and $b_{i}$ is max.

\subsubsection{Linkage among the Concepts}

The linkages between concepts are explained as follows:

Linkage 1(L1): The supply temperature (ST) has negative connection to supply temperature (ST).

Linkage 2(L2): The supply temperature (ST) has positive connection to supply humidity (SH).

Linkage 4(L4): The supply temperature (ST) has positive connection to the flow rate of fan (FF).

Linkage 5(L5): The supply temperature (ST) has positive connection to compressor speed (CS).

Linkage 7 (L7): The temperature of the room (TR) has negative connection to the temperature of the room (TR).

Linkage 8(L8): The temperature of the room (TR) has negative connection to the flow rate of fan (FF).

Linkage 9(L9): The temperature of the room (TR) has positive connection to speed of compressor (CS).

Linkage 10 (L10): The supply humidity (SH) has positive connection to supply humidity (SH).

Linkage 11 (L11): The supply humidity (SH) has positive connection to compressor speed (CS).

Linkage 12 (L12): The humidity of the room (HR) has positive effect to supply humidity (SH).

Linkage 13(L13): The humidity of the room (HR) has negative connection to humidity of the room (HR).

Linkage 14(L14): The humidity of the room (HR) has negative connection to the flow rate of fan (FF).

Linkage 15(L15): The humidity of the room (HR) has positive connection to compressor speed (CS).

Linkage 16(L16): The fan's flow rate (FF) has positive connection to temperature out from the evaporator (ST).

Linkage 17 (L17): The fan's flow rate (FF) has negative connection to temperature of the room (TR).

Linkage 18(L18): The fan's flow rate (FF) has positive connection to supply humidity (SH).

Linkage 19 (L19): The fan's flow rate (FF) has negative connection to humidity of the room (HR).

Linkage 20 (L20): The fan's flow rate (FF) has positive connection to fan's flow rate (FF).

Linkage 21 (L21): The compressor speed (CS) has positive connection to supply temperature (ST).

Linkage 22 (L22): The compressor speed (CS) has positive connection to temperature of the room (TR).

Linkage 23 (L23): The compressor speed (CS) has positive connection to supply humidity (SH).

Linkage 24 (L24): The compressor speed (CS) has positive connection to humidity of the room (HR).

Linkage 25 (L25): The compressor speed (CS) has positive connection to compressor speed (CS).

Figure 5 shows the graph structure of the proposed controller. 


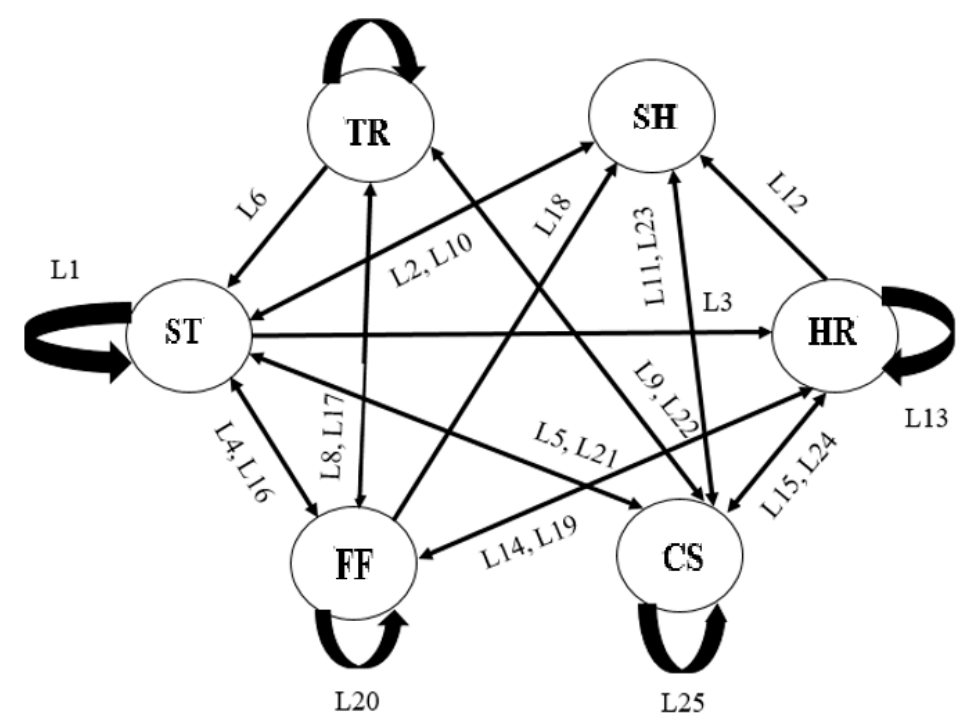

Figure 5. Schematic of proposed FCM controller.

\subsubsection{Allocating the Required Weights Based on the GPC Method}

Assigning the proper weights for the FCM concepts could lead to better and fast convergence of the desired values. This way, the performance will be increased due to the fast convergence of FCM to the desired set points. The GPC method will be a suitable solution to allocate the weights for the actuators which are the control signals [10]. As the FCM method is a type of fuzzy control method, all the weights should be normalized in the range of $[-1,1]$.

In the case of MIMO systems for finding the K matrix of GPC method, the steady space model is applied. Excluding the actuators, for other parameters of the system in FCM model, for converging the concepts to their operating point, the linearized model of the system is used around the operating point. In other words, the matrixes A and B of a steady space model are employed to describe the causal weights. If the concepts have direct relationships with each other, the values of the relations are adopted from matrixes A and B. For the other concepts with no relationship, if they have indirect relation with each other through the other concepts, the effect of the indirect relations should be used. At last, for the control signal concepts, the minimization values are calculated by GPC method to obtain the steady states (ss) or set points [24]. By calculation of the minimum of the $\left(u_{k}-u_{s s}\right)$, the minimum control efforts are achieved. All the weights should be fuzzified in the range of $[-1,1]$. In order to find the control law and closed loop poles of the system, the Equations (9)-(11) are used based on the steady space model of the system which is suitable for MIMO systems [25]:

$$
\begin{gathered}
X_{k+1}-X_{s s}=A\left(X_{k}-X_{s s}\right)+B\left(u_{k}-u_{s s}\right) \\
Y_{k}-Y_{s s}=C\left(X_{k}-X_{s s}\right) \\
u_{k}-u_{s s}=-k\left(X_{k}-X_{s s}\right)
\end{gathered}
$$

The $K$ matrix is calculated based on the GPC model procedure which is calculated by minimization of the performance index.

\subsubsection{Calculation of the Concepts Values}

In the proposed controller, Equations (12) and (13) are used to derive the control law. The values of the fan's flow rate and speed of compressor are calculated based on these two equations. The calculation procedure is continued until the calculated values in each iteration have no changes in comparison with the previous iteration. Then the calculation procedure stops. 


\section{Construction of FCM}

In consideration of a required scenario for the control algorithm, the FCM is illustrated by a fuzzy-graph construction of a few nodes based on the requirement of the control system as concepts to represent causal reasoning [26]. The system's condition or characteristic is displayed by every single concept [27]. Figure 6 indicates the diagram of FCM method as a graph structure.

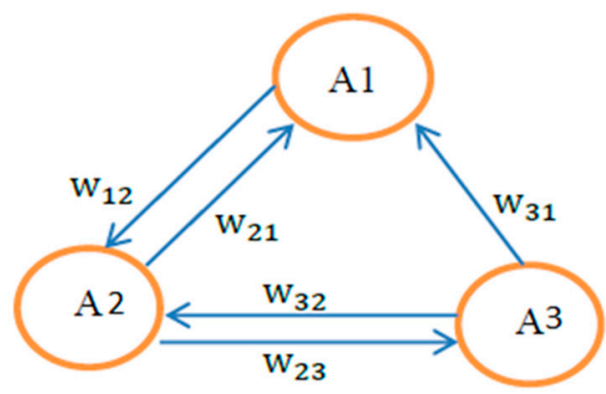

Figure 6. Schematic of FCM method.

The human knowledge about the operation of the system is represented by the FCM method and it can be developed based on the knowledge and experience of experts based on their experience about the model and behavior of the system [28]. The type, number of concepts and relationships among the concepts are determined by experts. The system behavior is determined by main factors which are known by experts and shown by concepts in the FCM structure. Regarding the experts' experiences, these concepts are extracted from the system's events, values, actions, goals and tendencies [29]. Based on the experts' recognition and experiences, the relationships between the elements are defined and they can be improved by using suitable weights between the concepts. In other words, the experts' knowledge about the system behavioral model is transformed in the form of weights. FCMs method is a combined method based on fuzzy logic method and artificial neural networks method which contains the robust characteristics of both methods [27,29].

The inputs and outputs of the system could easily be defined by the FCM method as nodes based on the control requirements of the system and expected operational scenario of the system. Thus, the MIMO approach could be met without the linearization of the system and limiting the operating range of the system. The other positive point of this structure is the causal relationship between the concepts in which the coupling effect between concepts could be considered as two side relationships between coupled parameters. This could improve the accuracy and sensitivity of the control system as close as the reality. Also, the definition of suitable range for the concept could prevent the overshoots and undershoots in the system. The FCM structure is able to define and limit the working range of the nodes, hence, the values of the nodes cannot exceed from these limits and may eliminate the overshoot and undershoot in the system. Moreover, the control law is derived from simple mathematics. The needs for measuring all states variables, additional measurements and a non-linear observer are omitted.

\section{Mathematical Description of FCM}

The structure of FCMs contains some concepts in which the value of each concept at a certain time is shown by $A_{i}$ in the system which indicates the activation degree of the mentioned parameter. These values are achieved by transforming the real values of parameters into the interval $[0,1]$. Weights among the concepts clarify the influence of parameters on each other and they are shown by $W_{i j}$. The values of weights are in the range from -1 to $1[27,30]$.

The relations of the concepts are divided into three categories as positive which reveal same effect between the mentioned concept on the other one, Zero relation which represents no relationship between two concepts, and negative displays opposite effect of the mentioned concept on the other 
one [27,29-31]. This graphical structure of the FCM method follows the specific mathematical model as a $1 \times \mathrm{n}$ state vector $(\mathrm{A})$ containing the values of the $\mathrm{n}$ concepts and an $\mathrm{n} \times \mathrm{n}$ weight matrix containing the weights $\left(W_{i j}\right)$ of the relationship among the nodes. The number of concepts is shown by $n$ [32].

The value of every single concept depends on the linked concepts with suitable weights and besides the previous value of the mentioned concept. The values of the concepts should be transformed to their fuzzy values. The activation level of $A_{i}$ for every single concept are calculated as follows [27,29-33]:

$$
A_{i}^{\text {new }}=f\left(\Sigma A_{j}^{\text {old }} \times W_{i j}\right)+A_{i}^{\text {old }}
$$

$A_{i}{ }^{\text {new }}$ clearly describes the concept $i$ activation value at time $t+1 . A_{j}{ }^{\text {old }}$ specifies the concept $j$ activation value at time $t . f$ is a sigmoid threshold function which compresses the values into the interval [0, 1] as follows [27,29-32]:

$$
f(x)=\frac{1}{\left(1+e^{-\lambda x}\right)}
$$

\subsubsection{Defuzzification of the Concept Values and Application to the Actuators}

Finally, the values of the actuators should be anti-normalized and applied to the actuators. Defuzzification of the actuator values has been done by Equations (14) and (15):

$$
\begin{gathered}
f=\left\{\begin{array}{cc}
0.3, & \text { if } A_{5}=0 \\
\left(A_{5} \times 0.1\right)+0.3, & \text { if } 0<A_{5} \leq 0.5 \\
{\left[0.1 \times\left(A_{5}-0.5\right)\right]+0.35,} & \text { if } 0.5<A_{5} \leq 1 \\
0.4, & \text { if } A_{5}=1
\end{array}\right. \\
s=\left\{\begin{array}{cc}
15, & \text { if } A_{6}=0 \\
\left(A_{6} \times 95\right)+15, & \text { if } 0<A_{6} \leq 0.5 \\
\left.95 \times\left(A_{6}-0.5\right)\right]+62.5, & \text { if } 0.5<A_{6} \leq 1 \\
110, & \text { if } A_{6}=1
\end{array}\right.
\end{gathered}
$$

\subsection{Stability Analysis of the Fuzzy Cognitive Map Method}

In order to analyze the stability of the FCM method, it should be consider as a one layer network Fuzzy Bidirectional Associative M emories (FBAMs) [34]. In other words, it can be considered as a special case of FBAMs which has one layer network instead of a two layers network. The FBAM structure consists of a two-layer neural network. It has two layers $X$ and $Y$. The connection matrixes from the $X$ layer to the $Y$ layer and vice versa are shown by matrix $P$ and matrix $R$. The triangular norms are used to justify the stability analysis of FBAMs [35]. The AND operation is generalized by triangular norms (T-norms) and the OR operation is generalized by T-conorm (S-norm). The connection matrixes between the layers are based on the max-T composition. If the S-T composition product of the connection matrixes converges to the max-T composition, the FBAM is globally stable. As the structure of FCM has one layer with one weight matrix, it can be considered as a two layers structure by decomposing the weight matrix $(\mathrm{W})$ into the two triangular matrices [34].

The LU factorization method, or Gaussian elimination method are used to decompose the weight matrix of FCM. The matrix $\mathrm{W}$ is square, which it is the product of a permutation of a lower triangular matrix (L) with ones on its diagonal and an upper triangular matrix $(\mathrm{U})$. The FCM weight matrix always can be decomposed into two triangular matrices due to the fuzzy values and directly and indirectly influence of the parameters on each other. The FCM structure is transformed into two-layers as layers $\mathrm{G}$ and $\mathrm{H}$, which the connection between the layers are shown by $\mathrm{L}$ and $\mathrm{U}$ matrices. The $\mathrm{L}$ matrix shows the relationship from layer $\mathrm{G}$ to $\mathrm{H}$, and the $\mathrm{U}$ matrix indicates it from layer $\mathrm{H}$ to $\mathrm{G}$. Number of concepts for each layer is the same as FCM concepts. Figure 7 shows the transformation of FCM structure into two layers designated as $\mathrm{G}$ and $\mathrm{H}$ [34]. 

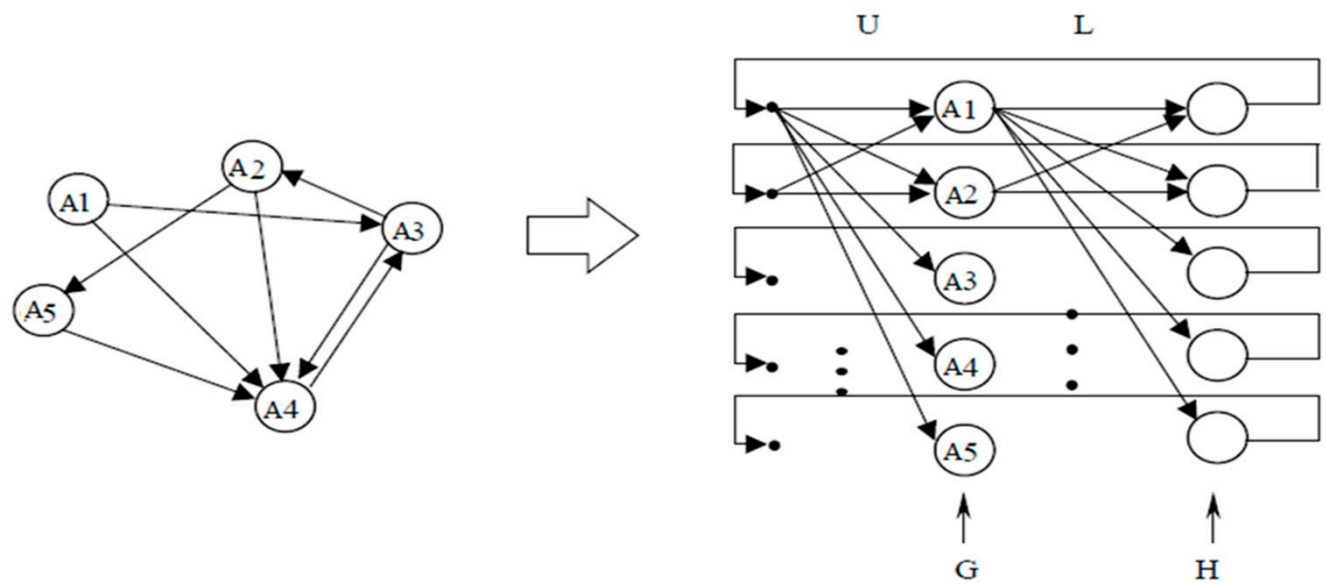

Figure 7. Transformation of FCM structure into two layers.

In order to prove the stability of FCM, a specific T-norm should exist from the S-T composition of the $L$ and $U$ matrices which should be equal to the original weight matrix. If this S-T composition exists, the FCM is globally stable. The product of S-T composition for two matrices $L=\left(l_{i j}\right) m \times p$ and $U=\left(u_{i j}\right) p \times n$ should be as follows [34]:

$$
\begin{gathered}
L \cdot U=\left(W_{i j}^{\prime}\right) \\
W_{i j}^{\prime}=\left(l_{i 1} T u_{1 i}\right) s\left(l_{i 2} T u_{2 i}\right) s \ldots s\left(l_{i p} T u_{p i}\right)
\end{gathered}
$$

Therefore, for the proposed designed controller, the weight matrix and factorization to the matrix $\mathrm{L}$ and $\mathrm{U}$ is as below. Consequently, as the weight matrix is the product of S-T composition of $\mathrm{L}$ and $\mathrm{U}$ matrices based on Equation (17), the designed controller is globally stable.

$$
\begin{aligned}
& L=\left[\begin{array}{cccccc}
-0.43734 & 0 & 0 & 0 & 0 & 0 \\
0 & 1 & 0 & 0 & 0 & 0 \\
1 & 0 & 0 & 0 & 0 & 0 \\
1 & 0 & 0 & 1 & 0 & 0 \\
0.66432 & 0.46333 & 0 & 0.73996 & 0.98796 & 0 \\
0.54409 & -0.52067 & 1 & 0 & 0 & 0
\end{array}\right] \\
& U=\left[\begin{array}{cccccc}
0.63795 & 0 & 0 & 0.45 & 0.7707 & 0.85448 \\
0 & -0.9 & 0 & 0 & -0.26662 & 0.2267 \\
0 & 0 & 0.84 & 0.73516 & -0.55815 & 0.65312 \\
0 & 0 & 0 & -1.35 & -1.5414 & 0.14241 \\
0 & 0 & 0 & 0 & 1.7735 & 1.0402 \\
0 & 0 & 0 & 0 & 0 & -1.8057
\end{array}\right] \\
& W=\left[\begin{array}{cccccc}
-0.279 & 0.9 & 0.6 & 0 & 0.9295 & 0.94095 \\
0 & -0.9 & 0 & 0 & -0.26662 & 0.2267 \\
0.63795 & 0 & 0 & 0.45 & 0.7707 & 0.85448 \\
0.63795 & 0 & 0 & -0.9 & -0.7707 & 0.99689 \\
0.4238 & -0.417 & 0 & -0.7 & 1 & 0 \\
0.3471 & 0.4686 & 0.84 & 0.98 & 0 & 1
\end{array}\right]
\end{aligned}
$$




\section{Results}

In this paper, the results of the controller are attained for the conditions of tropical countries like Malaysia, where the average air temperature is $30{ }^{\circ} \mathrm{C}$ and the humidity is $80 \%$. This controller is able to reduce the temperature to $25^{\circ} \mathrm{C}$ (this is in the acceptable range of thermal comfort temperature for tropical countries according to American Society of Heating, Refrigerating, and Air-Conditioning Engineers (ASHRAE) [36]) and the humidity to 50\% (also in the acceptable range of comfort humidity for tropical countries defined by ASHRAE [36]) [37-39]. The results in this section consist of three parts: set point tracking, performance analysis test by reference tracking by changing the set point and disturbance rejection, and finally, the comparison of the energy usage of the system in neighborhood of operating point for both the proposed GPC-FCM controller and the LQG controller from [8].

\subsection{Set point tracking}

The air-conditioned room temperature is indicated in Figure 8a. By changing the compressor speed and supply fan flow rate, the temperature of the air-conditioned room decreased from $30^{\circ} \mathrm{C}$ to $25.1^{\circ} \mathrm{C}$ at $380 \mathrm{~s}$. The air-conditioned room temperature reached to the desired set point in $6.3 \mathrm{~min}$ with $0.33 \%$ error and the temperature maintained at the desired set point. Figure $8 \mathrm{~b}$ shows the air-conditioned room humidity which is decreased from $0.02157 \mathrm{~kg} / \mathrm{Kg}$ to $0.00948 \mathrm{~kg} / \mathrm{Kg}$ at $1200 \mathrm{~s}$. By changing the speed of compressor and supply fan's flow rate, the air-conditioned room humidity decreased from $80 \%$ humidity to $48 \%$ humidity in 20 min with a $2.5 \%$ error from $50 \%$ humidity. The comfort humidity range of air-conditioned room in tropical countries is between $40 \%$ and $60 \%$. Then, the air-conditioned room humidity stabilized at $0.00948 \mathrm{~kg} / \mathrm{Kg}$.

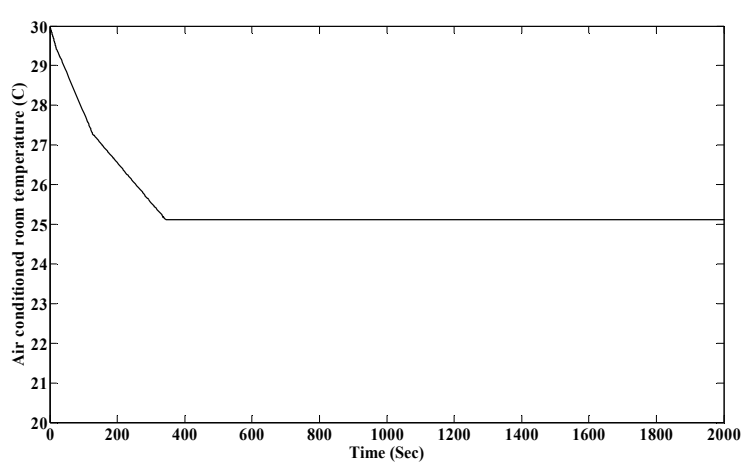

(a)

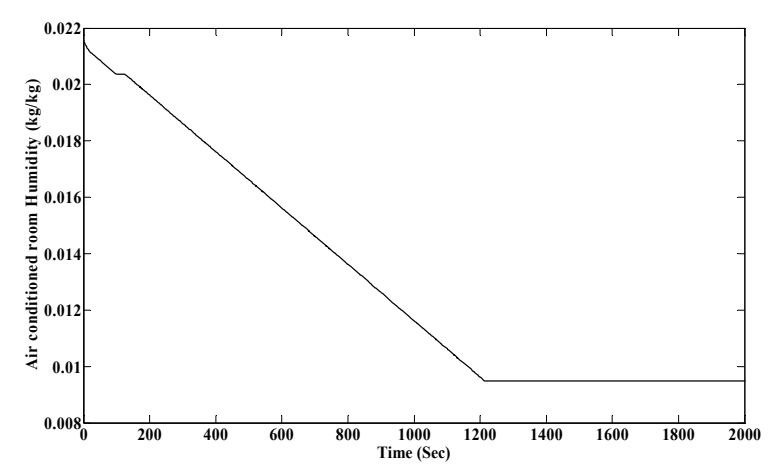

(b)

Figure 8. (a) Air-conditioned room temperature; (b) Air conditioned room humidity.

Figure 9a indicates the flow rate of the fan. In order to decrease the air-conditioned room temperature and humidity, the fan's flow rate increased from $0.34 \mathrm{~m}^{3} / \mathrm{s}$ to $0.382 \mathrm{~m}^{3} / \mathrm{s}$ and more or less stabilized around $0.382 \mathrm{~m}^{3} / \mathrm{s}$ and kept this flow rate until the temperature and humidity of the room reached the desired set points at $1173 \mathrm{~s}$. When the temperature and humidity of the room reached to the desired values at $1173 \mathrm{~s}$, the flow rate of the fan declined and maintained at $1200 \mathrm{~s}$ at $0.325 \mathrm{~m}^{3} / \mathrm{s}$ which is the minimum required value for the flow rate of the fan to keep the condition of the air-conditioned room in desired set points. Figure $9 \mathrm{~b}$ illustrates the compressor speed which increased from $3000 \mathrm{rpm}$ to $6359 \mathrm{rpm}$ and approximately stabilized about $6320 \mathrm{rpm}$ for declining the air-conditioned room temperature and humidity of. Then, from $1173 \mathrm{~s}$ to $1200 \mathrm{~s}$, the speed of the compressor decreased and maintained at $3960 \mathrm{rpm}$ to keep the air-conditioned room temperature and humidity in desired set points. 


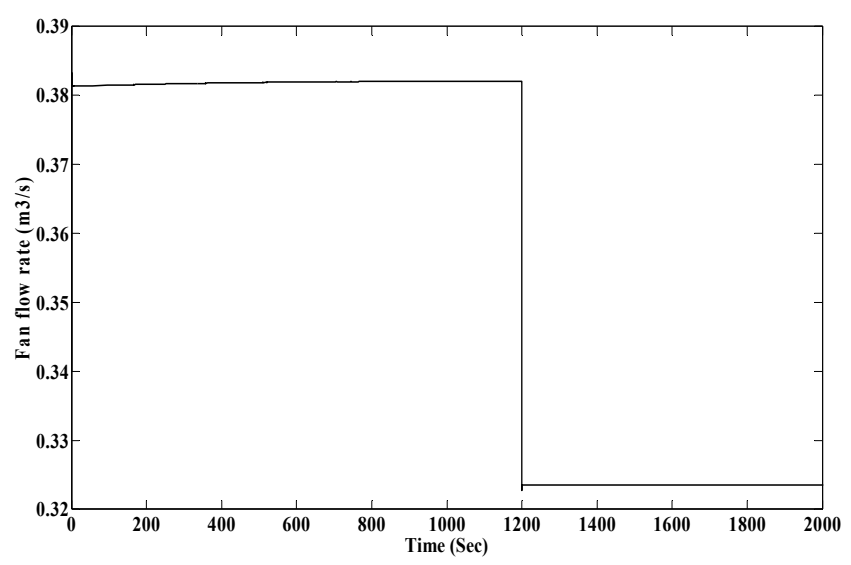

(a)

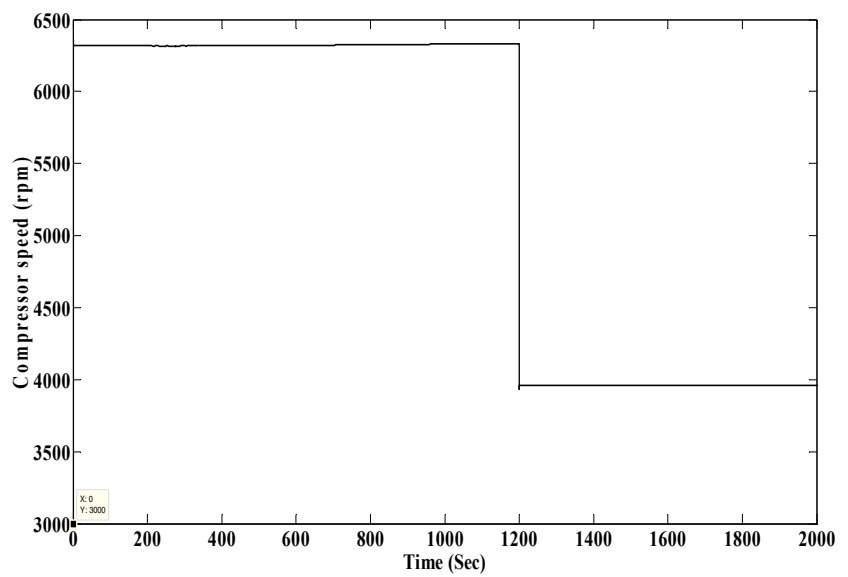

(b)

Figure 9. (a) Supply fan flow rate; (b) Compressor speed.

\subsection{Performance Analysis}

The performance and ability of the proposed controller was tested by two tests. The first test is set point tracking in which the set point was changed from $25^{\circ} \mathrm{C}$ to $23^{\circ} \mathrm{C}$, and also from $25^{\circ} \mathrm{C}$ to $26^{\circ} \mathrm{C}$ at $1300 \mathrm{~s}$. The second test is disturbance rejection test in which the values of the disturbances which are heat load and moisture load ( $Q_{\text {load }}$ and $M$ ) were changed from $4.49 \mathrm{~kW}$ and $0.96 \mathrm{Kg} / \mathrm{s}$ to $5.49 \mathrm{~kW}$ and $1.6 \mathrm{Kg} / \mathrm{s}$ respectively at $2000 \mathrm{~s}$.

\subsubsection{Reference Tracking by Changing the Set Point}

In order to show the ability of the controller, in the following set point tracking test the set point increased from $25{ }^{\circ} \mathrm{C}$ to $26{ }^{\circ} \mathrm{C}$ which is explained in the text in S3. Figure 10 shows the reference and actual temperature of the air-conditioned room. There is a change in the reference temperature from $25^{\circ} \mathrm{C}$ to $26{ }^{\circ} \mathrm{C}$ at $1300 \mathrm{~s}$. The initial room temperature is at $30^{\circ} \mathrm{C}$. It can be clearly seen that the proposed controller stabilized the temperature of the air-conditioned room at the first desired set point at 329 and stabilized the temperature at the second desired set point at $1417 \mathrm{~s}$, which is exactly $117 \mathrm{~s}$ after changing the set point. By decreasing the fan's flow rate and speed of the compressor, in $117 \mathrm{~s}$ the air conditioned room temperature increased and reached to the new set point. By changing the speed of compressor and supplying fan flow rate, the temperature of the air-conditioned room increased from $30{ }^{\circ} \mathrm{C}$ to $25.1^{\circ} \mathrm{C}$ for the first set point at $380 \mathrm{~s}$. The temperature reached to the desired set point in $6.3 \mathrm{~min}$ with $0.33 \%$ error and the temperature kept at the desired set point until $1300 \mathrm{~s}$ that the set 
point changed to the new one. For the second set point, the temperature of the air-conditioned room decreased from the $25.1{ }^{\circ} \mathrm{C}$ to $26.42^{\circ} \mathrm{C}$ in about $117 \mathrm{~s}$ and stabilized with $1.4 \%$ error from set point.

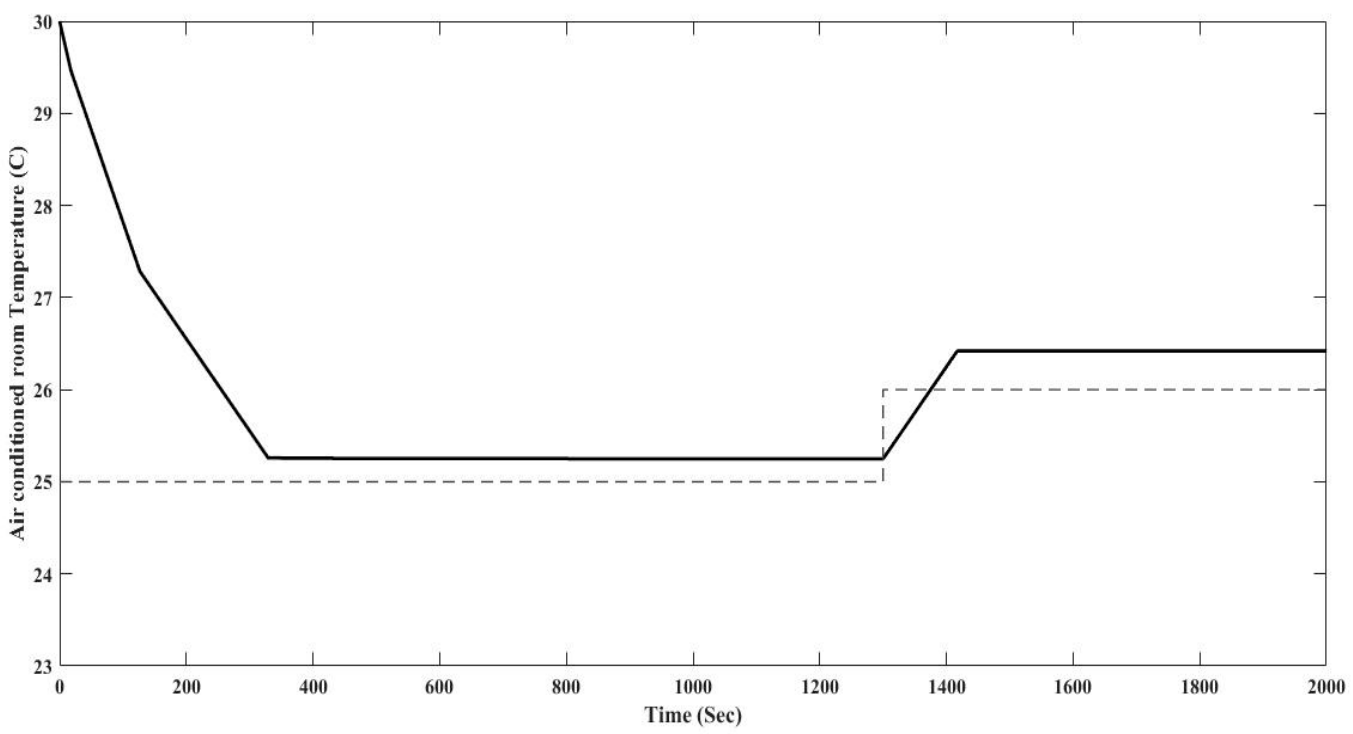

Figure 10. Air-conditioned room temperature in a reference tracking test with changes of set point to $26^{\circ} \mathrm{C}$.

The humidity of the air-conditioned room is demonstrated in Figure 11. The initial room humidity is set at $0.02157 \mathrm{~kg} / \mathrm{Kg}$ or $80 \%$. It can be clearly seen that the proposed controller stabilized the humidity at the desired set points in about $1221 \mathrm{~s}$. By changing the compressor speed and supply fan flow rate, the humidity of the air-conditioned room declined from $80 \%$ or $0.02157 \mathrm{~kg} / \mathrm{Kg}$ to $45 \%$ or $0.009425 \mathrm{~kg} / \mathrm{Kg}$ at about $1221 \mathrm{~s}$ or $20.35 \mathrm{~min}$ and stabilized with $6.25 \%$ error from $50 \%$ humidity. The humidity is still in the acceptable comfort range for the humidity in tropical regions that is in the domain of $40 \%$ to $60 \%$.

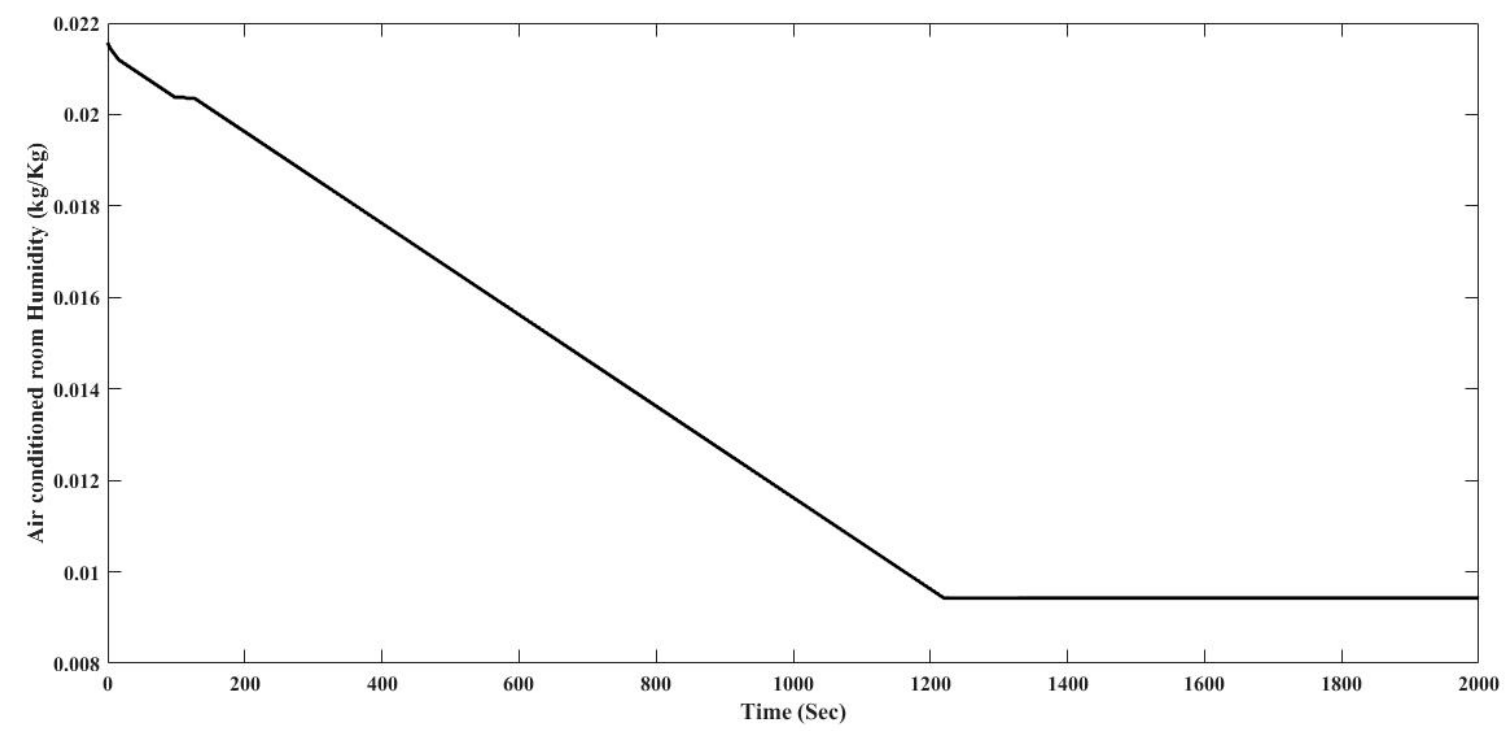

Figure 11. Air conditioned room humidity in a reference tracking test with changes of set point to $26^{\circ} \mathrm{C}$. 
The flow rate of the fan is indicated in Figure 12. The initial flow rate is at $0.34 \mathrm{~m}^{3} / \mathrm{s}$. It is clear that the proposed controller stabilized the flow rate at 700 for the first set point and after changing the set point at $1300 \mathrm{~s}$, it is stabilized at $1320 \mathrm{~s}$ which is exactly $20 \mathrm{~s}$ after changing the set point. For the first set point, by increasing the fan's flow rate from $0.34 \mathrm{~m}^{3} / \mathrm{s}$ to $0.382 \mathrm{~m}^{3} / \mathrm{s}$, the temperature and humidity of the air conditioned room decreased to $25.1{ }^{\circ} \mathrm{C}$ and $48 \%$ humidity and stabilized the flow rate of the fan at about $700 \mathrm{~s}$ and kept until $1173 \mathrm{~s}$. After reaching to the desired set point, the flow rate of the fan decreased to $0.3468 \mathrm{~m}^{3} / \mathrm{s}$ from $1173 \mathrm{~s}$ to $1200 \mathrm{~s}$ and kept stable until $1300 \mathrm{~s}$. Due to the set point changing at $1300 \mathrm{~s}$, in order to reach to the new set point, the flow rate of the fan decreased to $0.28 \mathrm{~m}^{3} / \mathrm{s}$, then when the temperature of the room reached to the new set point, the flow rate of the fan decreased to the minimum required value to keep the temperature and humidity of the room at desired set points, and finally stabilized at $0.28 \mathrm{~m}^{3} / \mathrm{s}$ at around $1320 \mathrm{~s}$ and maintained.

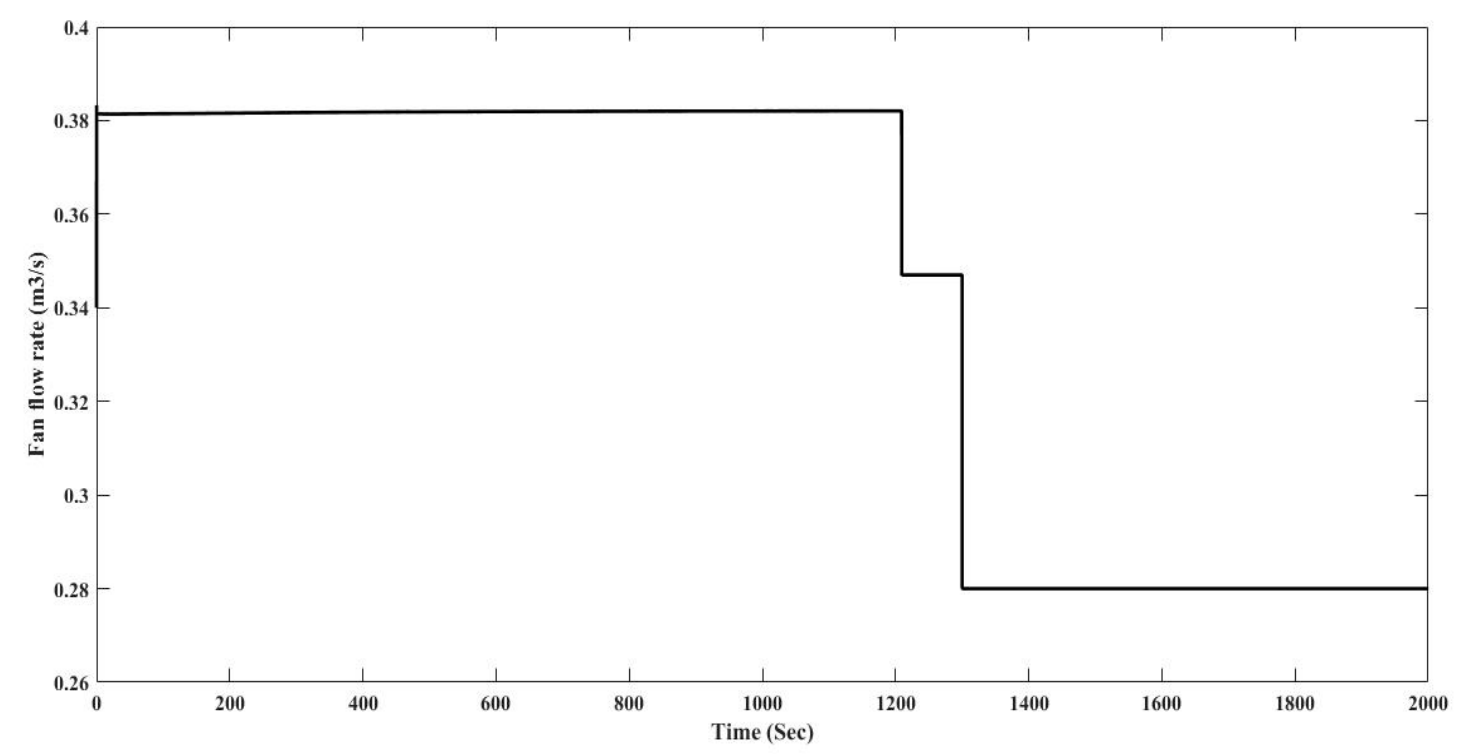

Figure 12. Supply fan flow rate in a reference tracking test with changes of set point to $26^{\circ} \mathrm{C}$.

The speed of the compressor is illustrated in Figure 13. The initial speed of the compressor is at $3000 \mathrm{rpm}$. It is clear that the proposed controller stabilized for first set point of the compressor speed at 1209 and for the second set point at $1320 \mathrm{~s}$, which is exactly $20 \mathrm{~s}$ after changing the set point. By increasing the compressor speed from $3000 \mathrm{rpm}$ to $6359 \mathrm{rpm}$ and keeping the situation around $6330 \mathrm{rpm}$ stable, the temperature of the room reached to the first set point at around $1200 \mathrm{~s}$. After reaching to the desired set point, the compressor speed decreased and maintained at $3949 \mathrm{rpm}$ which is the minimum required value to keep the condition from $1200 \mathrm{~s}$ to $1300 \mathrm{~s}$. After set point changing at $1300 \mathrm{~s}$, the compressor speed decreased to $3000 \mathrm{rpm}$ in order to reach to the new set point. When the temperature of the room reached to the new set point, the compressor speed decreased from $1300 \mathrm{~s}$ to $1320 \mathrm{~s}$ and maintained on $3000 \mathrm{rpm}$ to keep the condition of the room.

Figure 14 shows the reference and actual temperature of the air-conditioned room. There is a change in the reference temperature from $25^{\circ} \mathrm{C}$ to $23^{\circ} \mathrm{C}$ at $1300 \mathrm{~s}$. The initial room temperature is at $30^{\circ} \mathrm{C}$. It can be clearly seen that the proposed controller stabilized the temperature of the air conditioned room at the first desired set point at $380 \mathrm{~s}$ and stabilized the temperature at the second desired set point at $1325 \mathrm{~s}$, which is exactly $25 \mathrm{~s}$ after changing the set point. By increasing the flow rate of the fan and compressor speed, in $25 \mathrm{~s}$ the temperature of the air-conditioned room decreased and reached to the new set point. By changing the compressor speed and supply fan flow rate, the temperature of the air-conditioned room decreased from $30^{\circ} \mathrm{C}$ to $25.1{ }^{\circ} \mathrm{C}$ for the first set point at $380 \mathrm{~s}$. The temperature reached to the desired set point in $6.3 \mathrm{~min}$ with $0.33 \%$ error and the temperature maintained at the desired set point until $1300 \mathrm{~s}$ that the set point changed to the new one. For the 
second set point, the air-conditioned room temperature decreases from $25.1{ }^{\circ} \mathrm{C}$ to $23.6{ }^{\circ} \mathrm{C}$ in about $25 \mathrm{~s}$ and stabilized with $2 \%$ error from the set point.

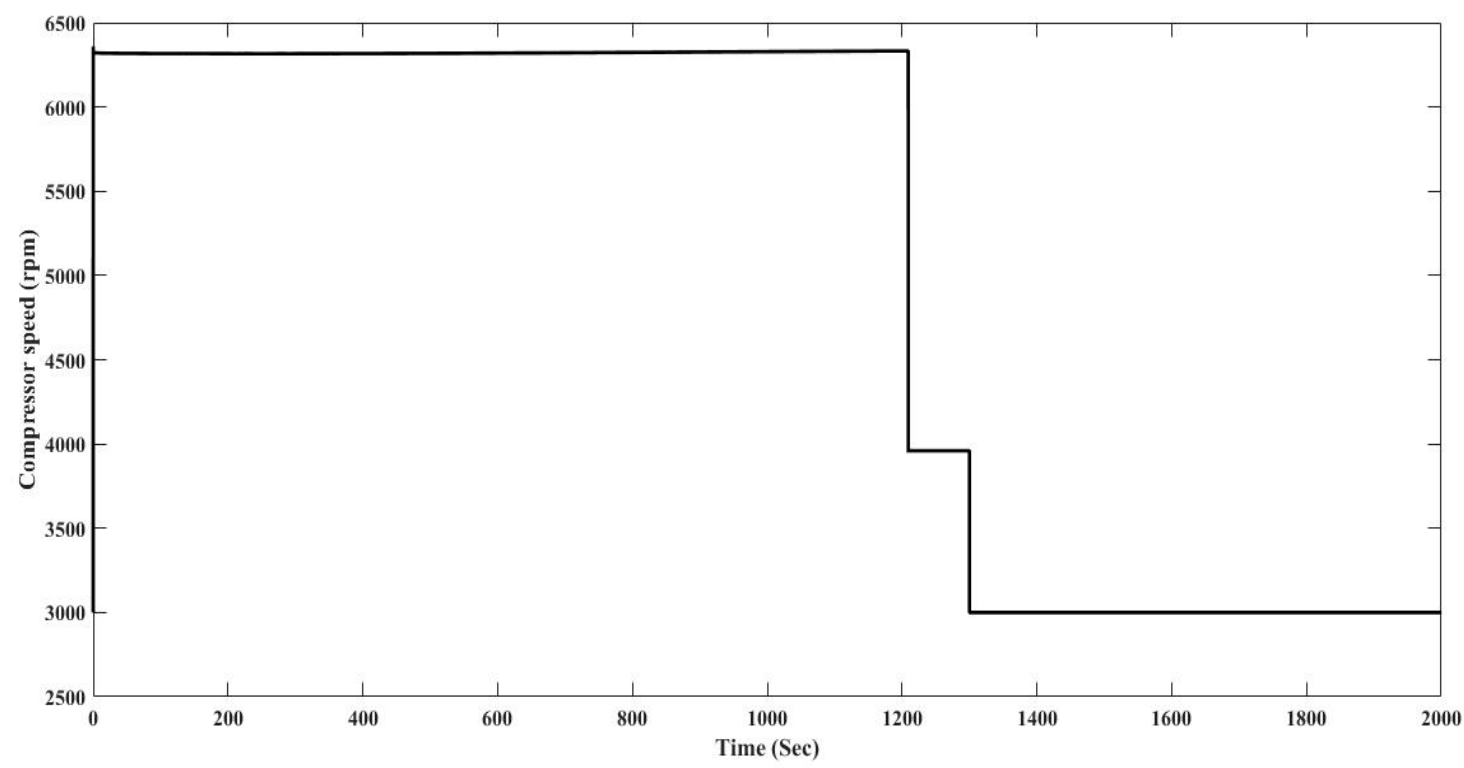

Figure 13. Compressor speed in a reference tracking test with changes of set point to $26^{\circ} \mathrm{C}$.

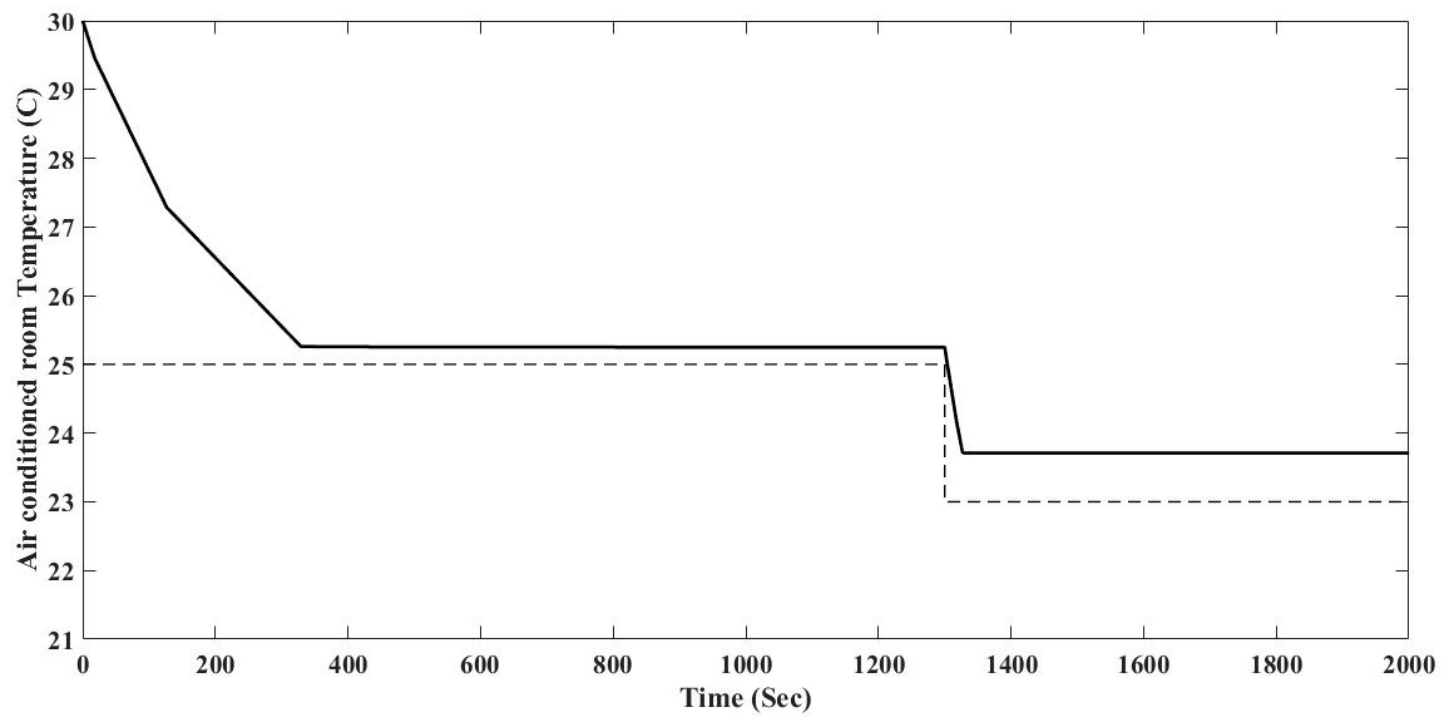

Figure 14. Air conditioned room temperature in a reference tracking test with changes of set point to $23{ }^{\circ} \mathrm{C}$.

The humidity of the air-conditioned room is illustrated in Figure 15. The initial room humidity is at $0.02157 \mathrm{~kg} / \mathrm{Kg}$ or $80 \%$. It can be clearly seen that the proposed controller stabilized the humidity at the first desired set point at $1200 \mathrm{~s}$ and stabilized the humidity at the second desired set point at $1357 \mathrm{~s}$, which is exactly $57 \mathrm{~s}$ after changing the set point. The humidity declined from $80 \%$ or $0.02157 \mathrm{~kg} / \mathrm{Kg}$ to $48 \%$ or $0.00948 \mathrm{~kg} / \mathrm{Kg}$ at about $1200 \mathrm{~s}$. After changing the set point at $1300 \mathrm{~s}$ the humidity reached to $0.009977 \mathrm{~kg} / \mathrm{Kg}$ or $53.5 \%$ at $1357 \mathrm{~s}$ and stabilized. By changing the compressor speed and supply fan flow rate, the air-conditioned room humidity decreased from $80 \%$ humidity to $48 \%$ humidity in 20 min with $2.5 \%$ error from $50 \%$ humidity for the first set point and for the s set point it reached to the desired set point in about $1 \mathrm{~min}$ with $4.3 \%$ error from $50 \%$ humidity. The humidity is still in the acceptable comfort range for humidity in tropical regions that is in the domain of $40 \%$ to $60 \%$. 


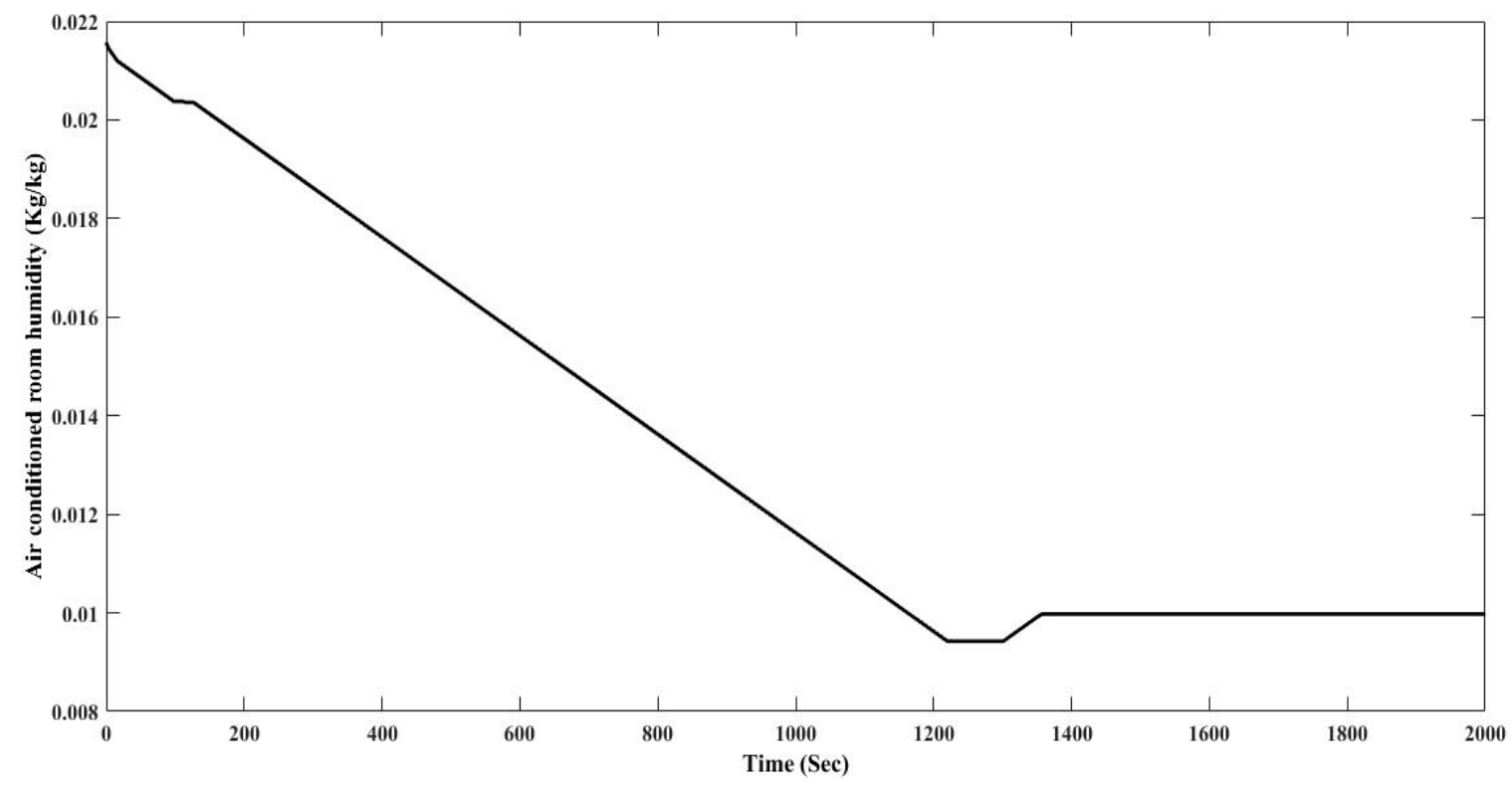

Figure 15. Air conditioned room humidity in a reference tracking test with changes of set point to $23^{\circ} \mathrm{C}$.

The flow rate of the fan is indicated in Figure 16 . The initial flow rate is at $0.34 \mathrm{~m}^{3} / \mathrm{s}$. It is clear that the proposed controller stabilized the flow rate at 1200 for the first set point and after changing the set point at $1300 \mathrm{~s}$, it is stabilized at $1339 \mathrm{~s}$, which is exactly $39 \mathrm{~s}$ after changing the set point. For the first set point, by increasing the fan's flow rate from $0.34 \mathrm{~m}^{3} / \mathrm{s}$ to $0.382 \mathrm{~m}^{3} / \mathrm{s}$, the temperature and humidity of the air-conditioned room decreased to $25.1{ }^{\circ} \mathrm{C}$ and $48 \%$ humidity and stabilized the flow rate of the fan until $1173 \mathrm{~s}$. After reaching to the desired set point, the flow rate of the fan decreased to the to $0.325 \mathrm{~m}^{3} / \mathrm{s}$ from $1173 \mathrm{~s}$ to $1200 \mathrm{~s}$ and kept stable until $1300 \mathrm{~s}$. Due to the set point changing at $1300 \mathrm{~s}$, in order to reach to the new set point, the flow rate of the fan increased to $0.8815 \mathrm{~m}^{3} / \mathrm{s}$, then when the temperature of the room reached to the new set point, the flow rate of the fan decreased to the minimum required value to keep the temperature and humidity of the room at desired set points and finally stabilized at $0.34 \mathrm{~m}^{3} / \mathrm{s}$ at around $1339 \mathrm{~s}$ and remained maintained.

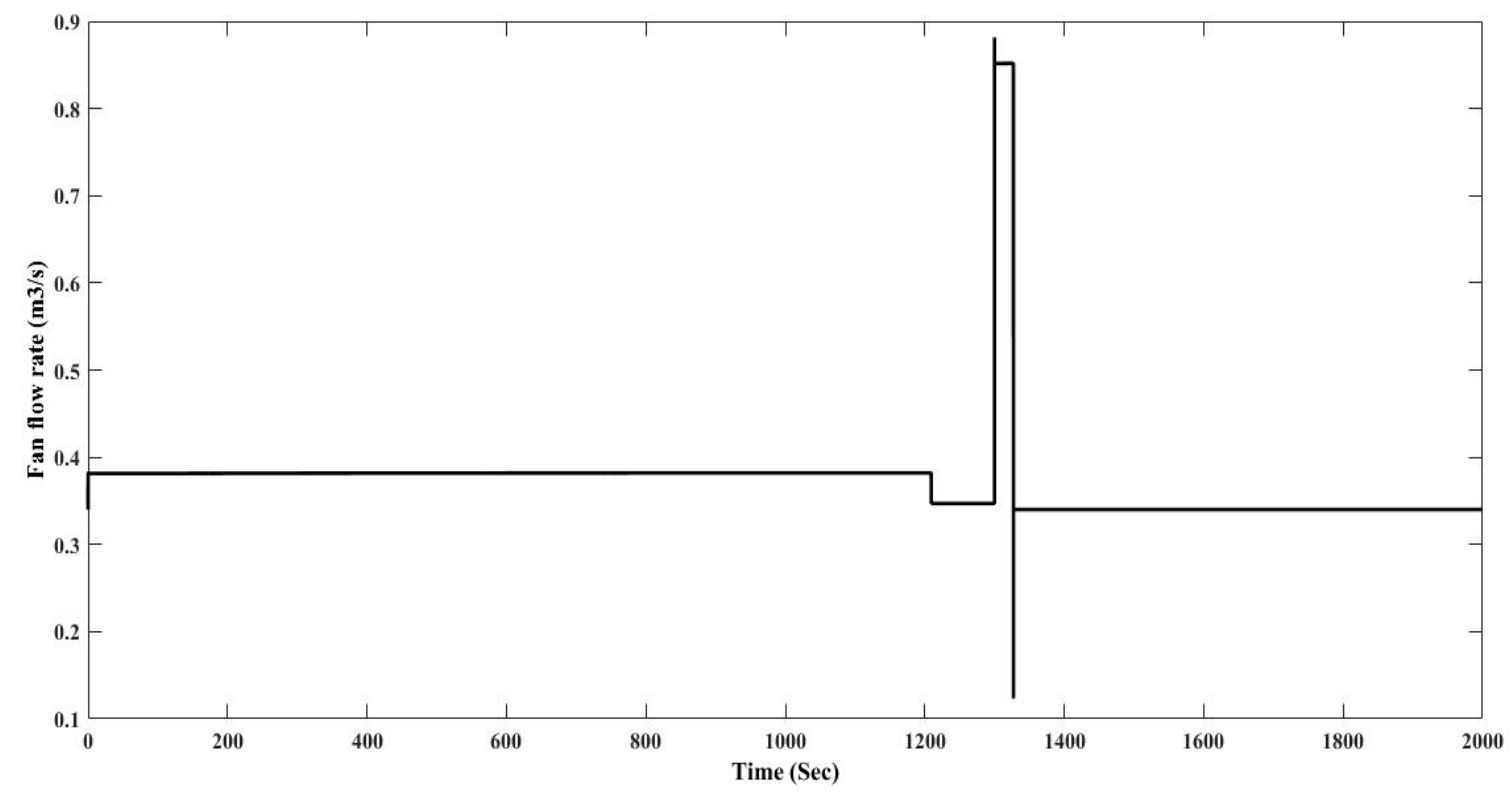

Figure 16. Supply fan flow rate in a reference tracking test with changes of set point to $23^{\circ} \mathrm{C}$. 
The speed of compressor is illustrated in Figure 17. The initial speed of the compressor is set at $3000 \mathrm{rpm}$. It is clear that the proposed controller stabilized the first set point of the compressor speed at 1200 and for the second set point at $1334 \mathrm{~s}$, which is exactly $34 \mathrm{~s}$ after changing the set point. By increasing the compressor speed from $3000 \mathrm{rpm}$ to $6359 \mathrm{rpm}$ and kept stable the situation around $6320 \mathrm{rpm}$, the temperature of the roomed reach to first set point at around $1200 \mathrm{~s}$. After reaching to the desired set point, the compressor speed decreased and maintained at $3960 \mathrm{rpm}$ which is the minimum required value to keep the condition from $1200 \mathrm{~s}$ to $1300 \mathrm{~s}$. After the set point changing at $1300 \mathrm{~s}$, the compressor speed raised to $6326 \mathrm{rpm}$ in order to reach to the new set point. When the temperature of the room reached to the new set point, the compressor speed decreased from $1327 \mathrm{~s}$ to $1334 \mathrm{~s}$ and maintained on $3180 \mathrm{rpm}$ to keep the condition of the room.

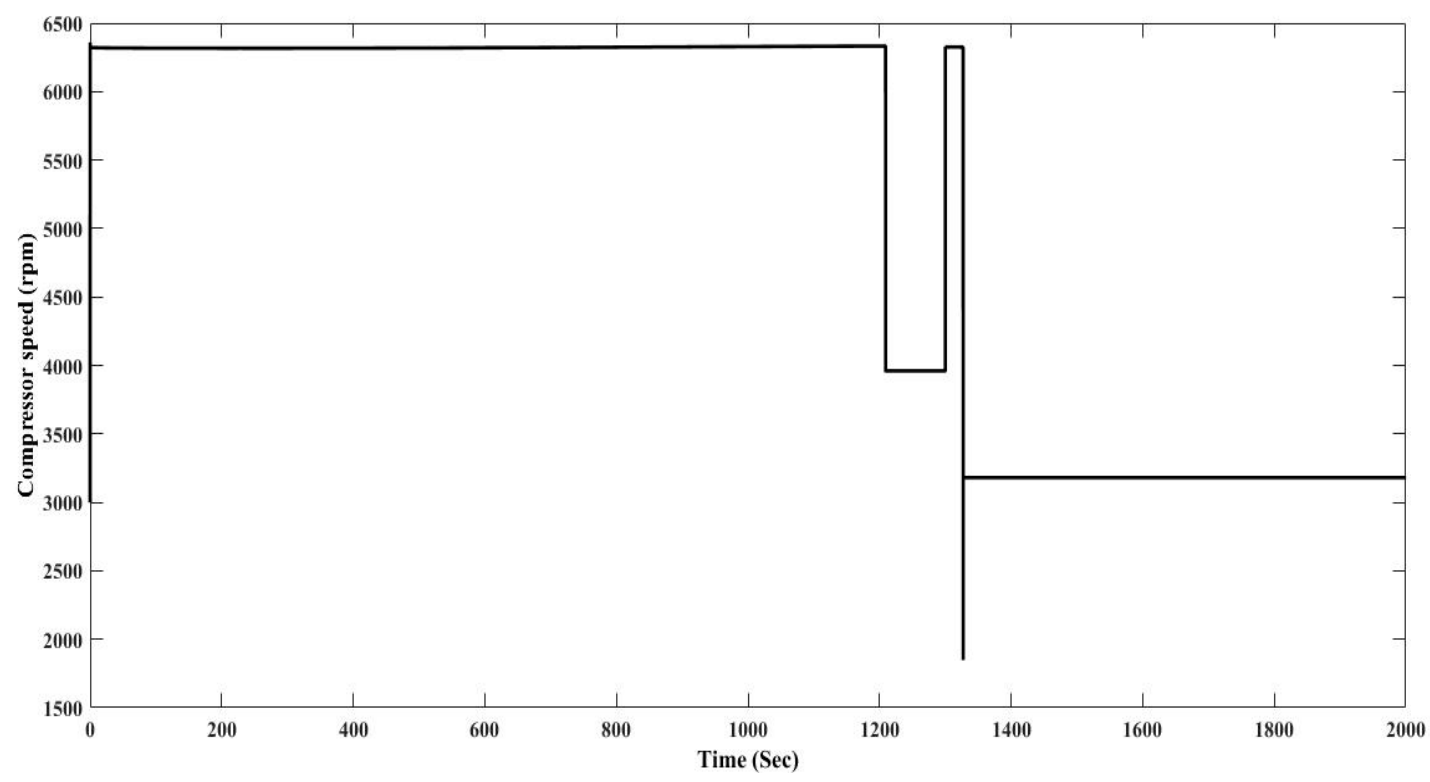

Figure 17. Compressor speed in a reference tracking test with changes of set point to $23^{\circ} \mathrm{C}$.

\subsubsection{Disturbance Rejection}

The results in this section emphasize on the ability of the controller to control and maintain the outputs of the system at desired set points in the presence of disturbances. In this case, by varying the supply fan flow rate and speed of the compressor, the air-conditioned room temperature and humidity have been controlled and maintained at the desired set points. In this test, at $2000 \mathrm{~s}$ the heat load and moisture load changed from $4.49 \mathrm{~kW}$ and $0.96 \mathrm{Kg} / \mathrm{s}$ to $5.49 \mathrm{~kW}$ and $1.6 \mathrm{Kg} / \mathrm{s}$, respectively.

The air-conditioned room temperature with disturbance rejection is shown in Figure 18. At $2000 \mathrm{~s}$ by increasing the heat load in the room, the air-conditioned room temperature increased gradually and at around $2050 \mathrm{~s}$. Due to the increasing air-conditioned room, the temperature and exceed from the acceptable range for desired set point, the speed of the compressor and supply fan increased to reject the disturbances in the room. By increasing the compressor speed and flow rate of the fan, the temperature of the room started to decrease slowly and at $2100 \mathrm{~s}$ maintained at $25.6{ }^{\circ} \mathrm{C}$ which is in the acceptable range. The disturbances rejected and the temperature reached to the desired set point in 1.66 min with $2 \%$ error and the temperature maintained at the desired set point. 


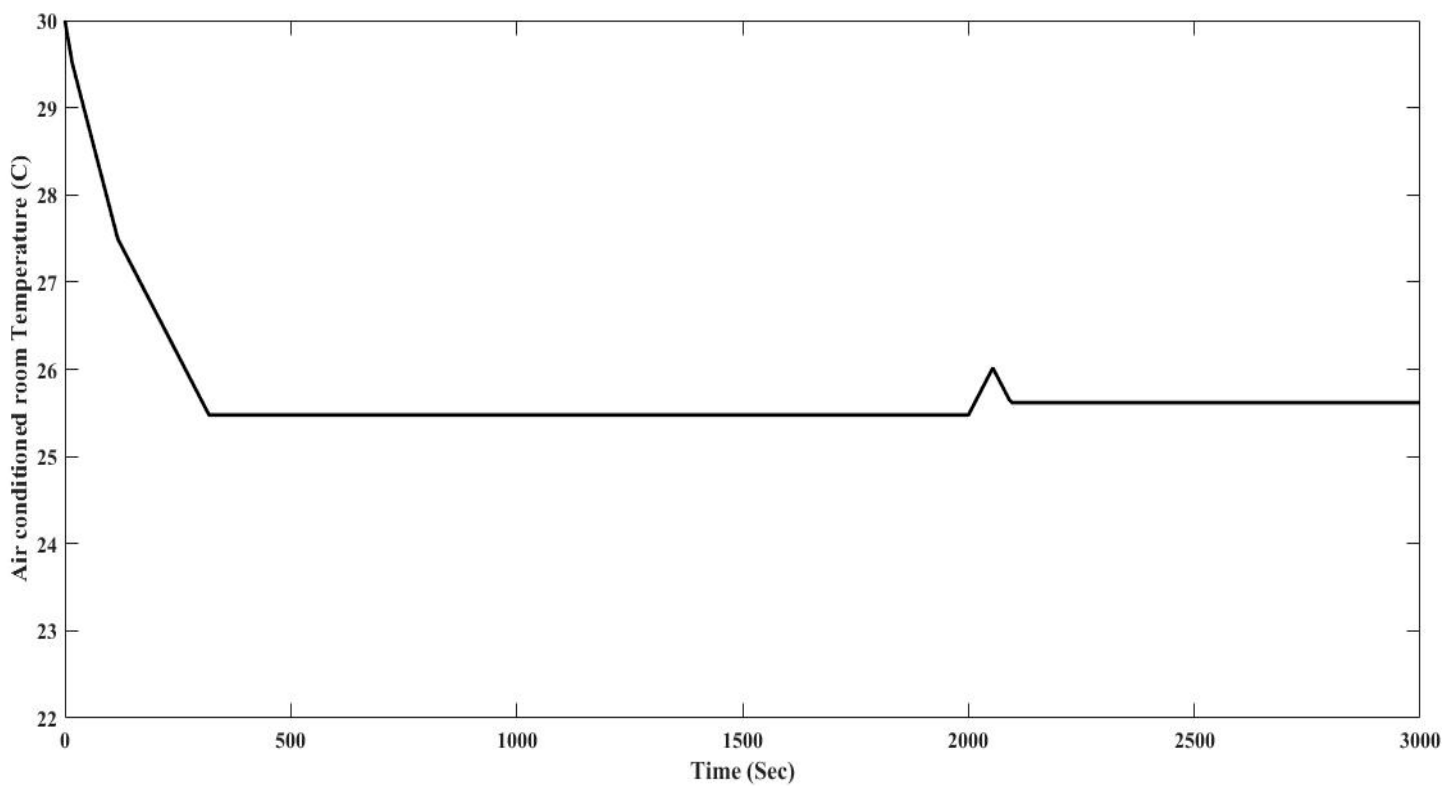

Figure 18. Air conditioned room temperature in a disturbance rejection test.

By increasing the moisture load at $2000 \mathrm{~s}$, the air-conditioned room humidity increased slowly from $0.009863 \mathrm{~kg} / \mathrm{Kg}$ to $0.01008 \mathrm{~kg} / \mathrm{Kg}$ at around $2050 \mathrm{~s}$ and reached to the $0.0101 \mathrm{~kg} / \mathrm{Kg}$ and maintained which is indicated in Figure 19. By increasing the speed of compressor and flow rate of the fan, the disturbances rejected and the humidity of the room kept at $49.5 \%$ humidity which is at the acceptable range for the air-conditioned room humidity. The humidity kept at desired set point with $0.625 \%$ error from $50 \%$ humidity.

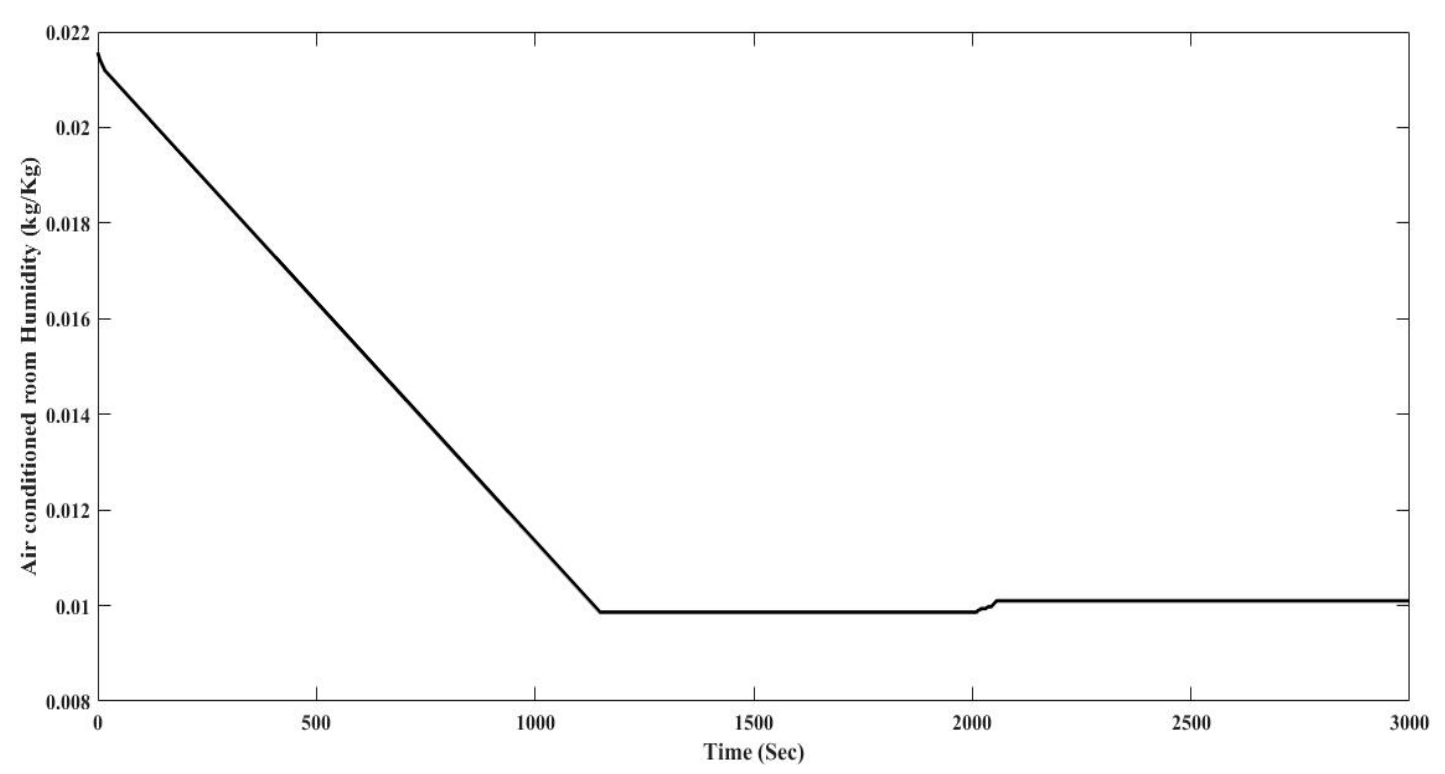

Figure 19. Air conditioned room humidity in a disturbance rejection test.

In Figure 20 the flow rate of the supply fan is indicated. By increasing the moisture and heat load in room at $2000 \mathrm{~s}$, the temperature and humidity of the room increased, then as they exceed their acceptable ranges for the desired set points, the flow rate of the fan increased sharply from $0.341 \mathrm{~m}^{3} / \mathrm{s}$ at $2046 \mathrm{~s}$ to $0.4595 \mathrm{~m}^{3} / \mathrm{s}$ at $2066 \mathrm{~s}$ and remained at this value which is the minimum required value to reject the disturbances and keep the temperature and humidity of the room at desired set points. 


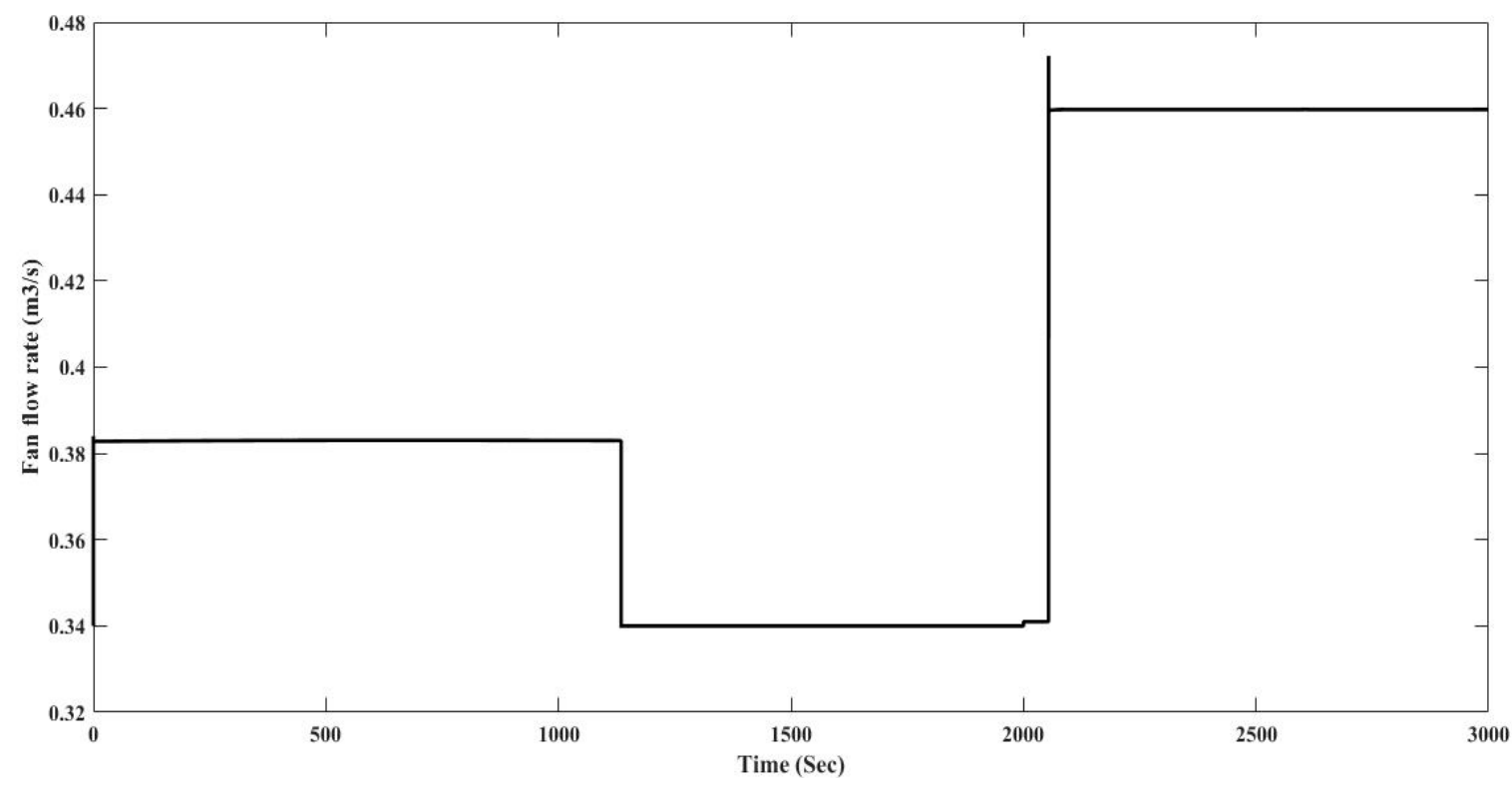

Figure 20. Fan flow rate in a disturbance rejection test.

Figure 21 shows the compressor speed. By increasing the moisture and heat load in room at $2000 \mathrm{~s}$, the temperature and humidity of the room increased, then as they exceed from their acceptable ranges for desired set points, the compressor speed increased from $4140 \mathrm{rpm}$ at $2054 \mathrm{~s}$ to $6332 \mathrm{rpm}$ at about $2066 \mathrm{~s}$ and became stable at this value which is the minimum required value to reject the disturbances and keep the temperature and humidity of the room at desired set points.

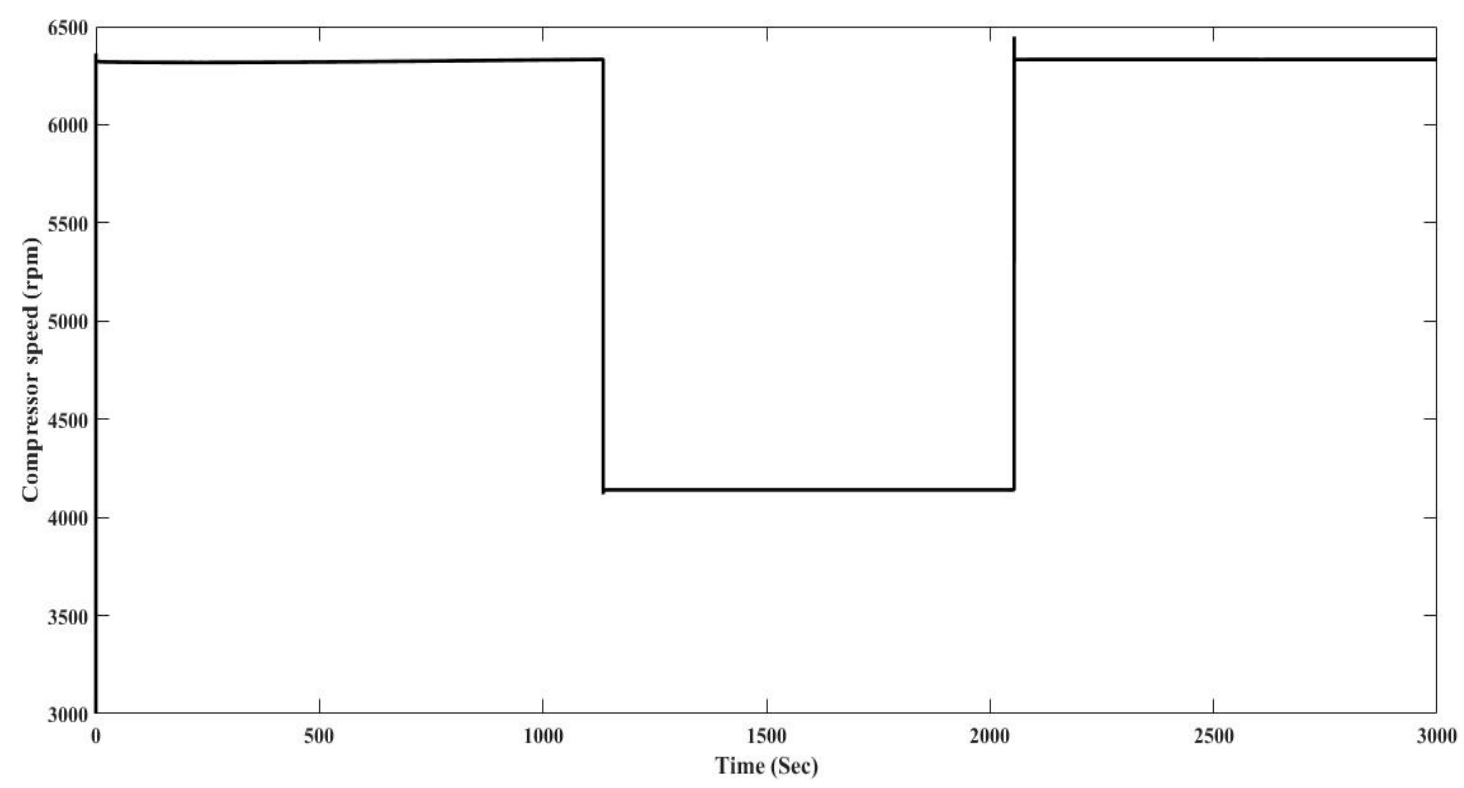

Figure 21. Compressor speed in a disturbance rejection test.

\subsection{Comparison the Energy Consumption and Performance Indexes of GPC-FCM with LQG}

This section compares the obtained results based on the proposed GPC-FCM controller with LQG controller based on [8] works. The comparison of results by GPC-FCM controller with the LQG controller is not arbitrary. As a suitable criterion to compare the GPC-FCM controller results on the same system, the LQG controller which is the previous work on this system is chosen. In order to 
compare the performance of both controllers, performances and energy consumption of them which are applied on the same DX A/C system are compared in the same condition. As the LQG controller was designed as a MIMO controller on the linearized model of the system, it can only work properly around the operating point of the system. In order to compare both controllers, they were tested under the same conditions around the operating point. The initial air conditioned room temperature is considered $26^{\circ} \mathrm{C}$ and the initial air conditioned room humidity is considered $0.01057 \mathrm{~kg} / \mathrm{Kg}$ and the desired temperature and humidity are considered $25^{\circ} \mathrm{C}$ and $0.00988 \mathrm{~kg} / \mathrm{Kg}$, respectively. In the same situation, the energy consumption of both controllers was calculated.

The temperature of the air-conditioned room by GPC-FCM controller is shown in Figure 22. The temperature decreased from $26^{\circ} \mathrm{C}$ to $25.1^{\circ} \mathrm{C}$ in about $82 \mathrm{~s}$ and remained steady. By increasing the compressor speed and flow rate of the fan by increasing the supply fan speed, the temperature decreased from $26^{\circ} \mathrm{C}$ to $25.1^{\circ} \mathrm{C}$ in about $82 \mathrm{~s}$. The temperature reached the desired set point in $1.36 \mathrm{~min}$ with $0.33 \%$ error and the temperature was maintained at the desired set point. Figure 23 indicates the air conditioned room humidity by GPC-FCM controller which is decreased from $0.01057 \mathrm{~kg} / \mathrm{Kg}$ to $0.00999 \mathrm{~kg} / \mathrm{Kg}$ in about $70 \mathrm{~s}$ and maintained. By increasing the speed of compressor and fan's flow rate by increasing the supply fan speed, the air conditioned room humidity decreased from $50 \%$ humidity for $26^{\circ} \mathrm{C}$ to $50 \%$ for $25.1{ }^{\circ} \mathrm{C}$ in 1.16 min with no error from $50 \%$ humidity.

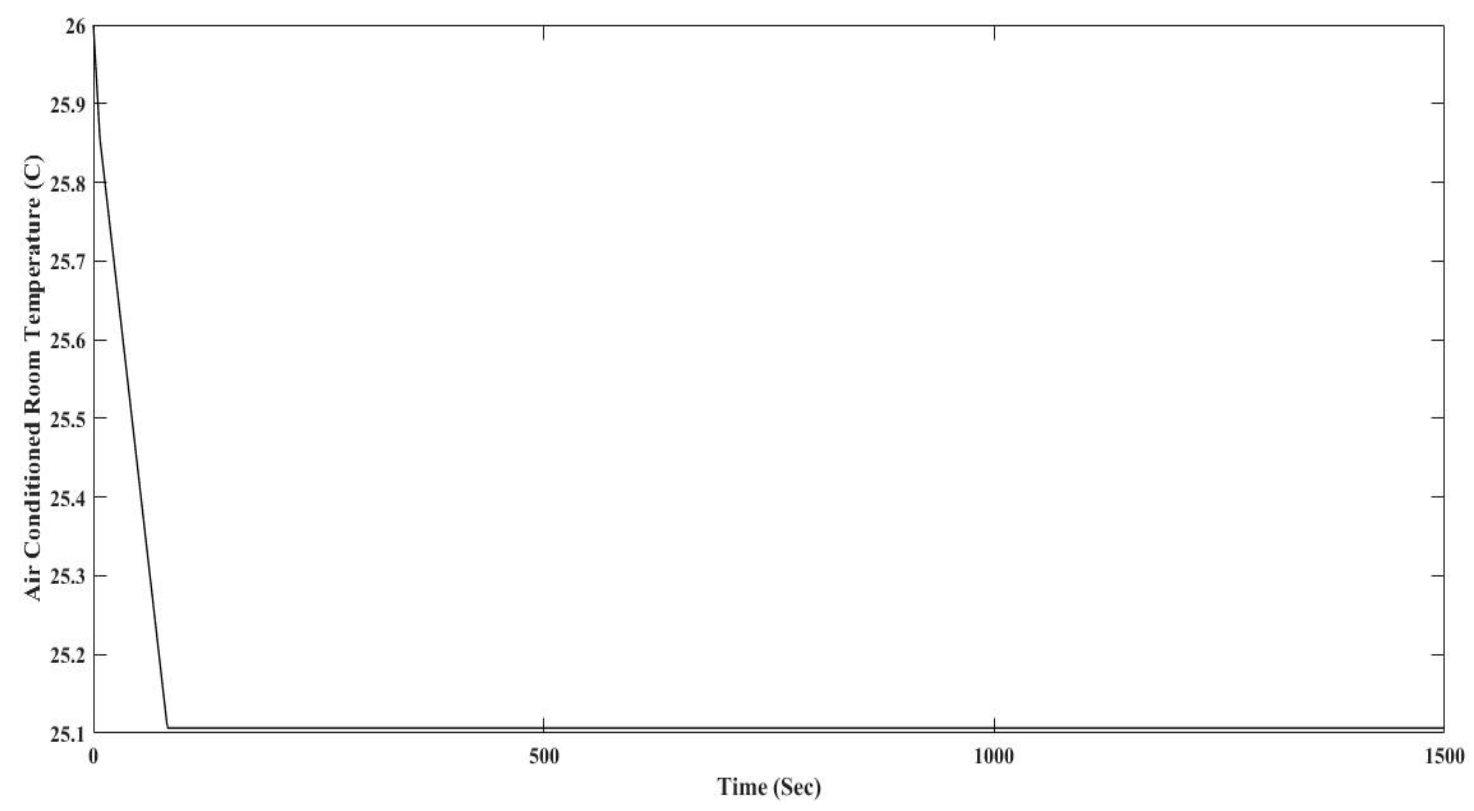

Figure 22. The temperature of air conditioned room by GPC-FCM controller.

The speed of the supply fan is indicated in Figure 24. The speed of the fan increased from $2120 \mathrm{rpm}$ to $2488 \mathrm{rpm}$ and was maintained at $63 \mathrm{~s}$, then it decreased to $2120 \mathrm{rpm}$ at $72 \mathrm{~s}$ and was maintained. At $63 \mathrm{~s}$ when the temperature of the room reached to the desired values, the speed of the fan started to decrease until it reached to the required speed for keeping the air-conditioned room temperature and humidity at the desired set points. The speed of the fan decreased to $2120 \mathrm{rpm}$ at $72 \mathrm{~s}$ and maintained the speed. 


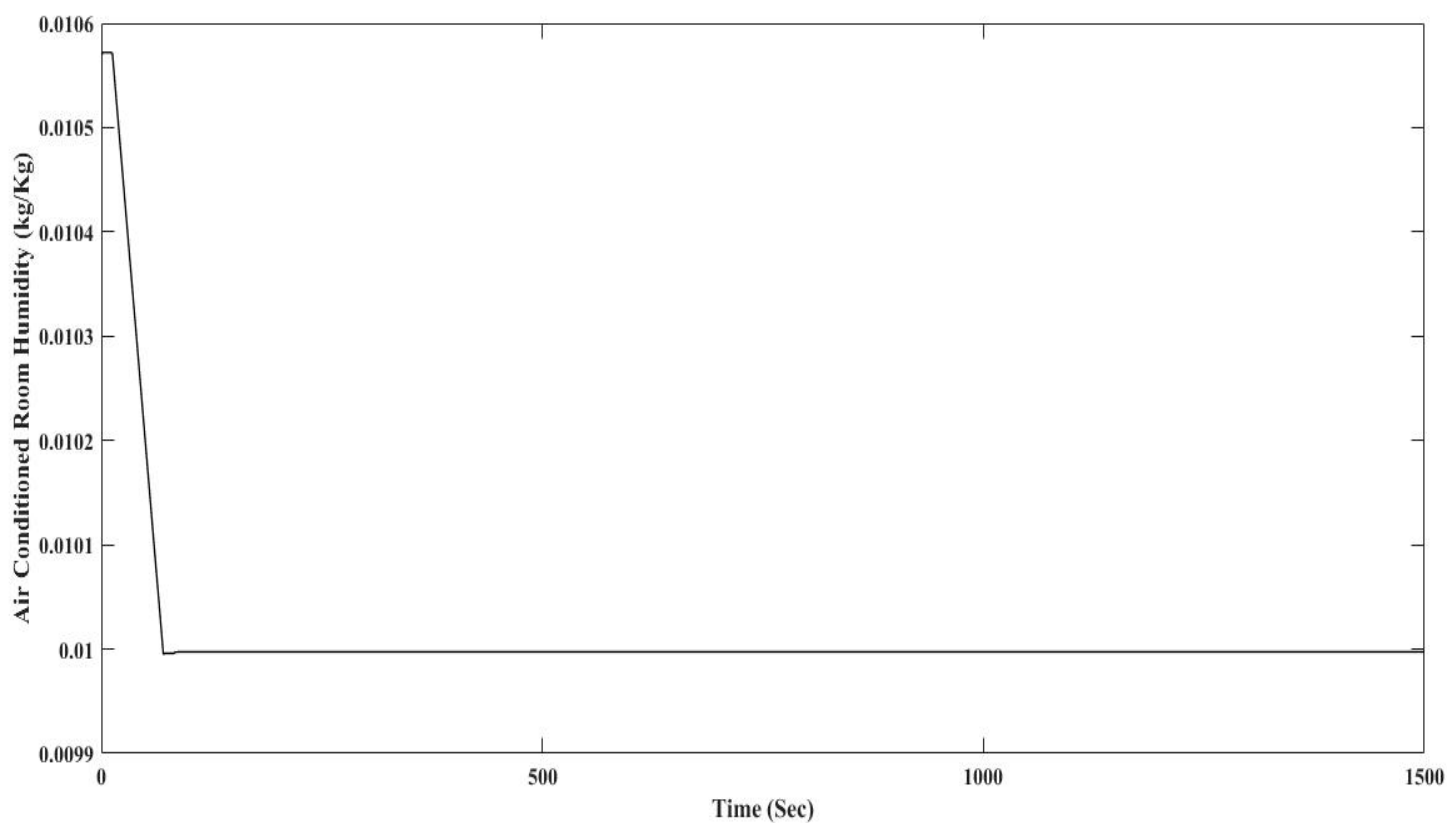

Figure 23. The humidity of air conditioned room by GPC-FCM controller.

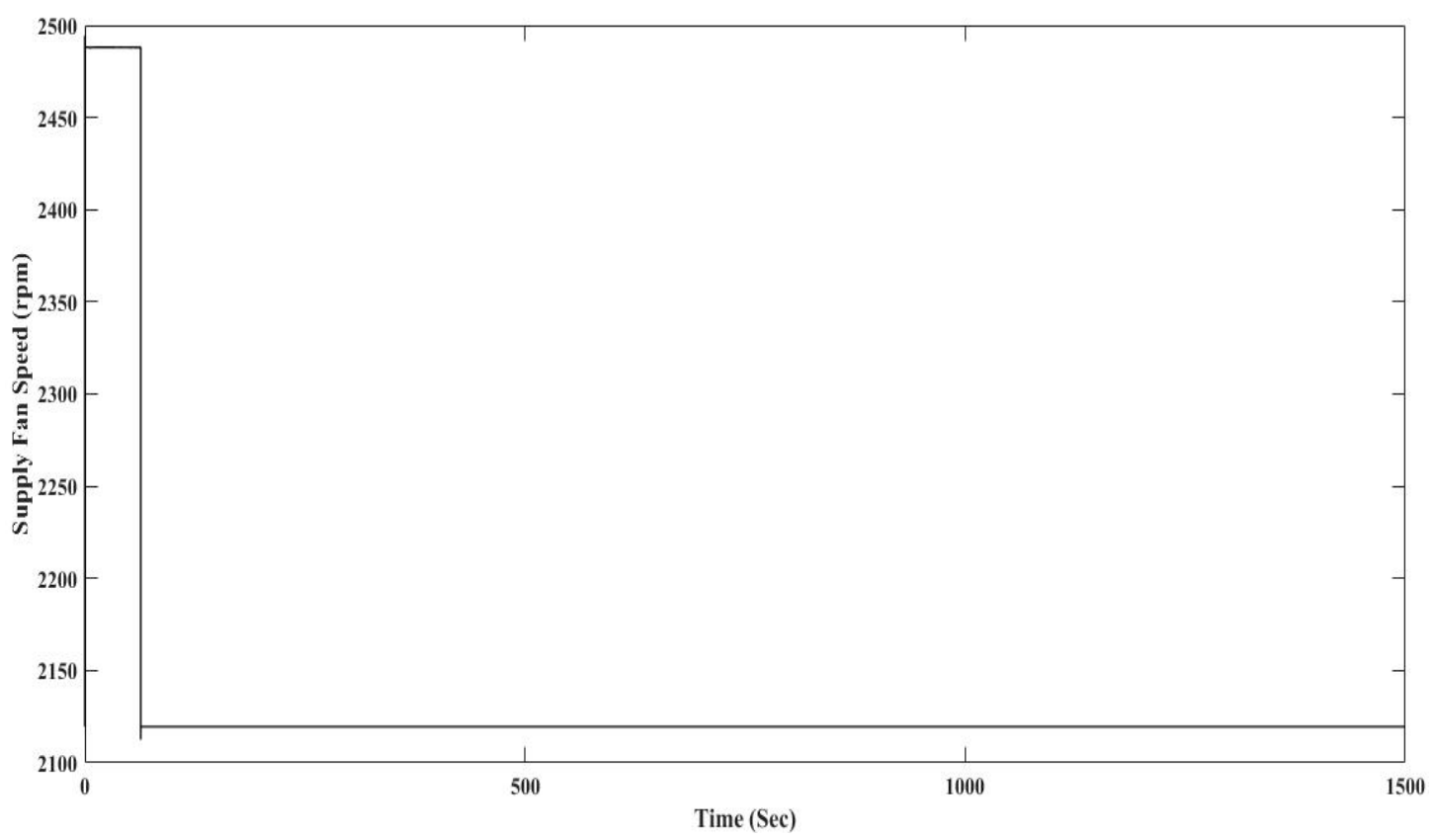

Figure 24. The speed of supply fan by GPC-FCM controller.

Figure 25 shows the speed of the compressor. To decrease the temperature of the air-conditioned room, the compressor speed increased from $3000 \mathrm{rpm}$ to $6333 \mathrm{rpm}$ in $10 \mathrm{~s}$ and was then maintained until $62 \mathrm{~s}$, then by declining the air-conditioned room temperature to the desired value, the speed of the compressor decreased and maintained at $4140 \mathrm{rpm}$ at $74 \mathrm{~s}$ and maintained to keep the air conditioned room temperature and humidity in desired set points. 


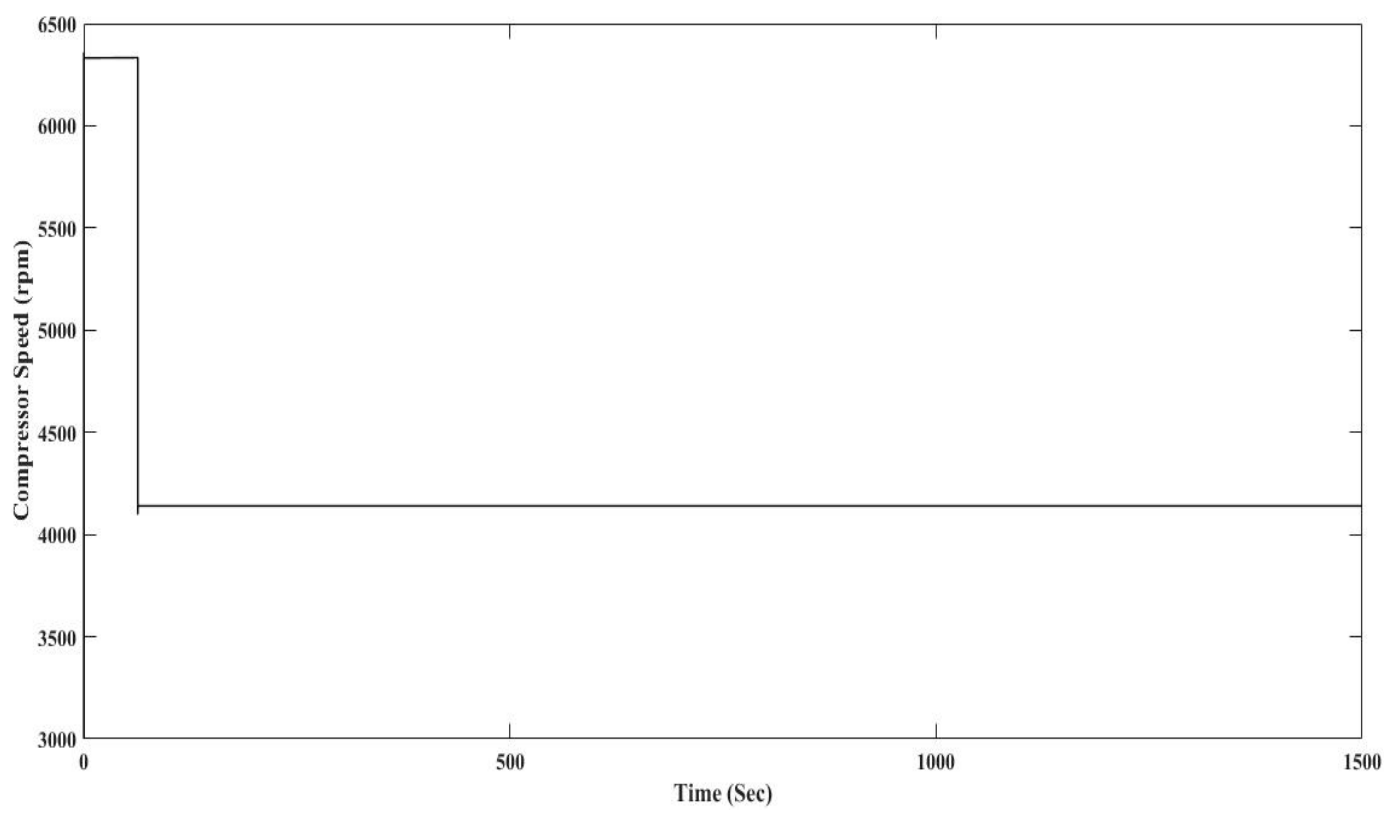

Figure 25. The speed of compressor by GPC-FCM controller.

In $1500 \mathrm{~s}$, the energy usage by compressor is $6.349 \times 10^{6}(\mathrm{~W})$ and energy usage by supply fan is $3.203 \times 10^{6}(\mathrm{~W})$. The total energy usage by applying GPC-FCM controller is $9.552 \times 10^{6}(\mathrm{~W})$.

The temperature of the air conditioned room by LQG controller is shown in Figure 26. The temperature decreased from $26^{\circ} \mathrm{C}$ and oscillated around $25^{\circ} \mathrm{C}$ in about $1148 \mathrm{~s}$ and was maintained. By increasing the compressor speed and flow rate of the fan, the temperature decreased from $26^{\circ} \mathrm{C}$ to $25^{\circ} \mathrm{C}$ in about $1148 \mathrm{~s}$. The temperature reached the desired set point in $19.13 \mathrm{~min}$ with a $2.6 \%$ error and the temperature was maintained at the desired set point.

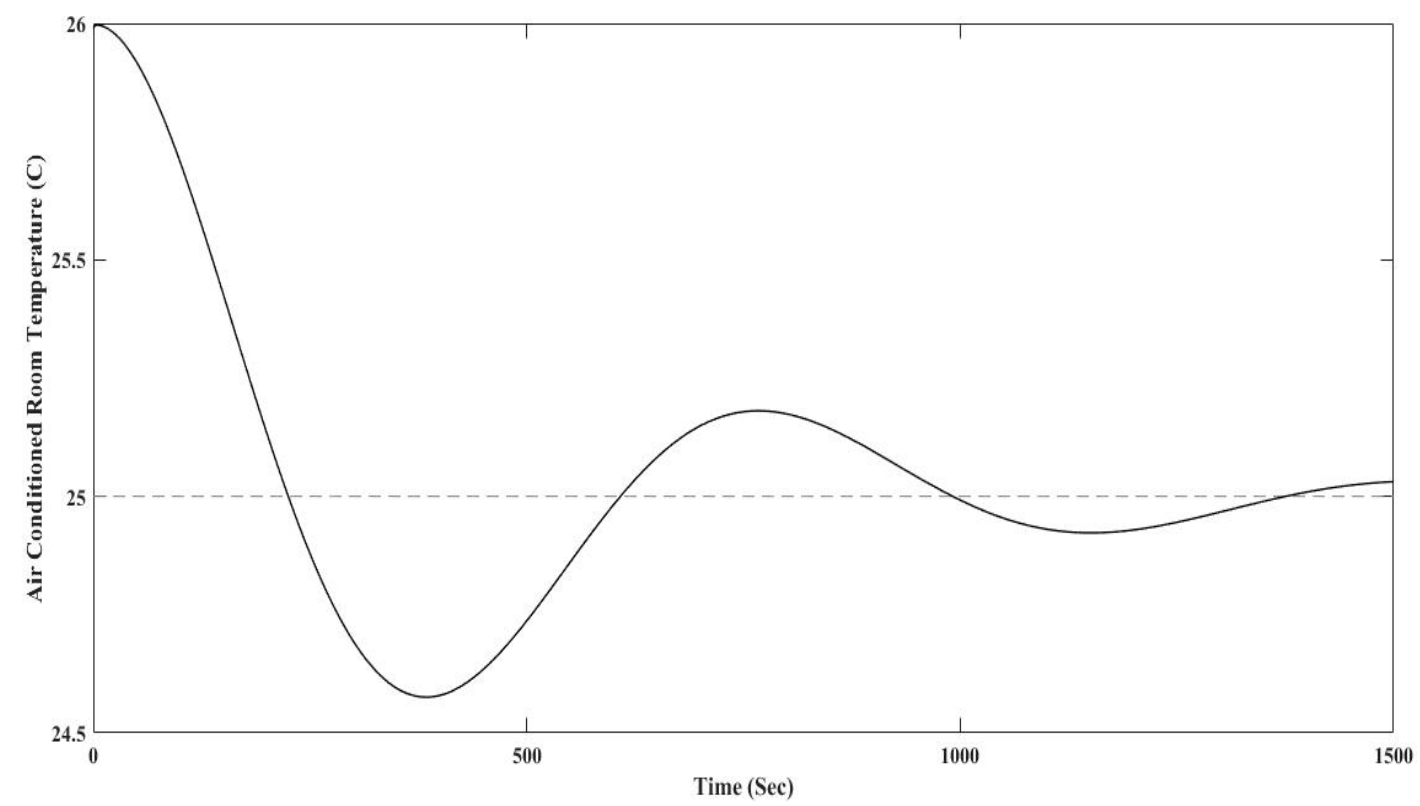

Figure 26. The temperature of air conditioned room by LQG controller.

Figure 27 indicates the air-conditioned room humidity established by the LQG controller which decreased from $0.01057 \mathrm{~kg} / \mathrm{Kg}$ to $0.00901 \mathrm{~kg} / \mathrm{Kg}$ in about $1342 \mathrm{~s}$ and was maintained. By increasing 
the compressor speed and flow rate of the fan, the humidity of the air-conditioned room decreased from $50 \%$ humidity for $26^{\circ} \mathrm{C}$ to $46.1 \%$ for $25{ }^{\circ} \mathrm{C}$ in 22.36 min with $4.8 \%$ error from $50 \%$ humidity.

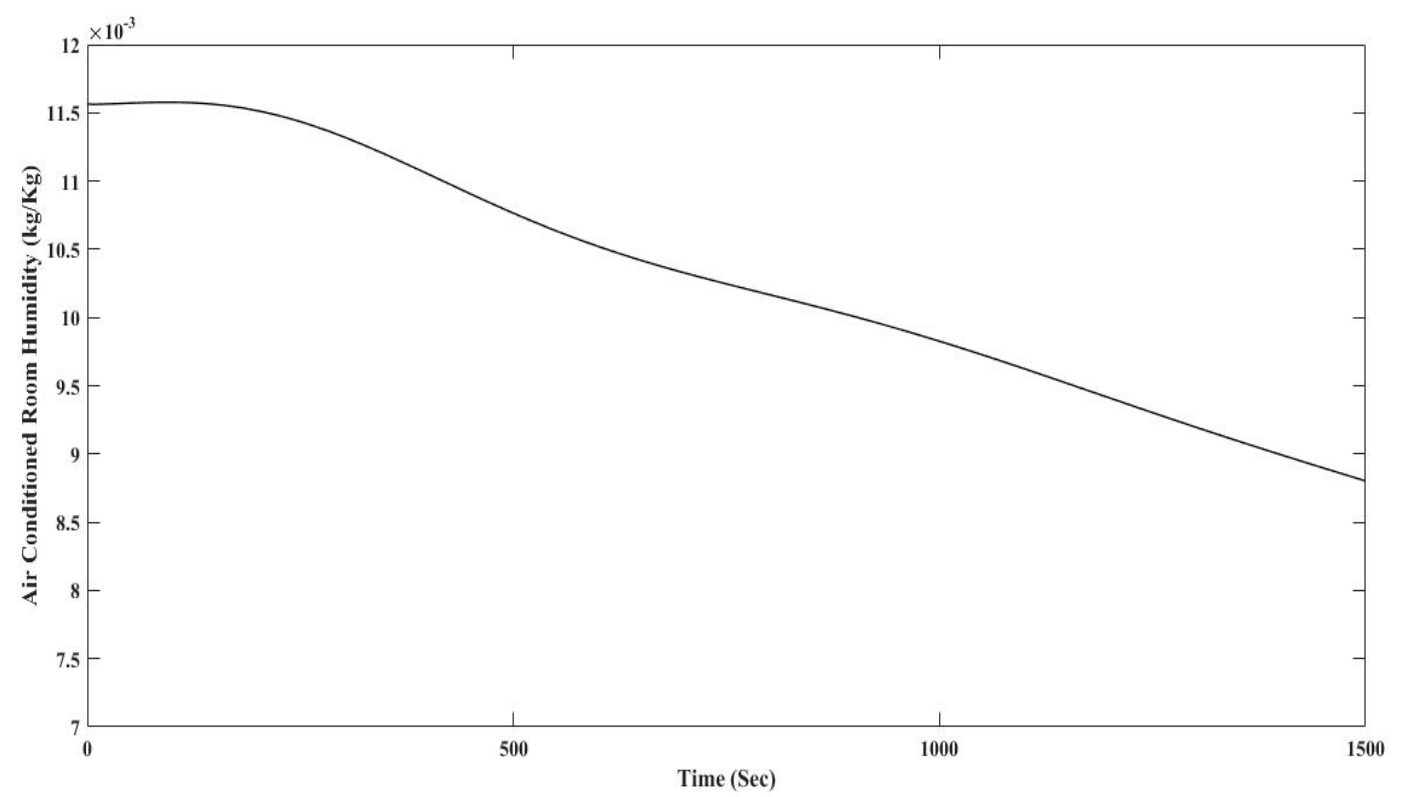

Figure 27. The humidity of air conditioned room by LQG controller.

The speed of the supply fan is indicated in Figure 28. The speed of the fan increased from $2120 \mathrm{rpm}$ to $2595 \mathrm{rpm}$ at $220 \mathrm{~s}$ then decreased to $2321 \mathrm{rpm}$ at $609 \mathrm{~s}$ and finally reached $2515 \mathrm{rpm}$ at $1204 \mathrm{~s}$ and was maintained. When the temperature of the room reached the desired values, the speed of the fan started to decrease until it reached the required speed for keeping the air-conditioned room temperature and humidity at the desired set points. The speed of fan decreased to $2515 \mathrm{rpm}$ at $1204 \mathrm{~s}$ and maintained the speed.

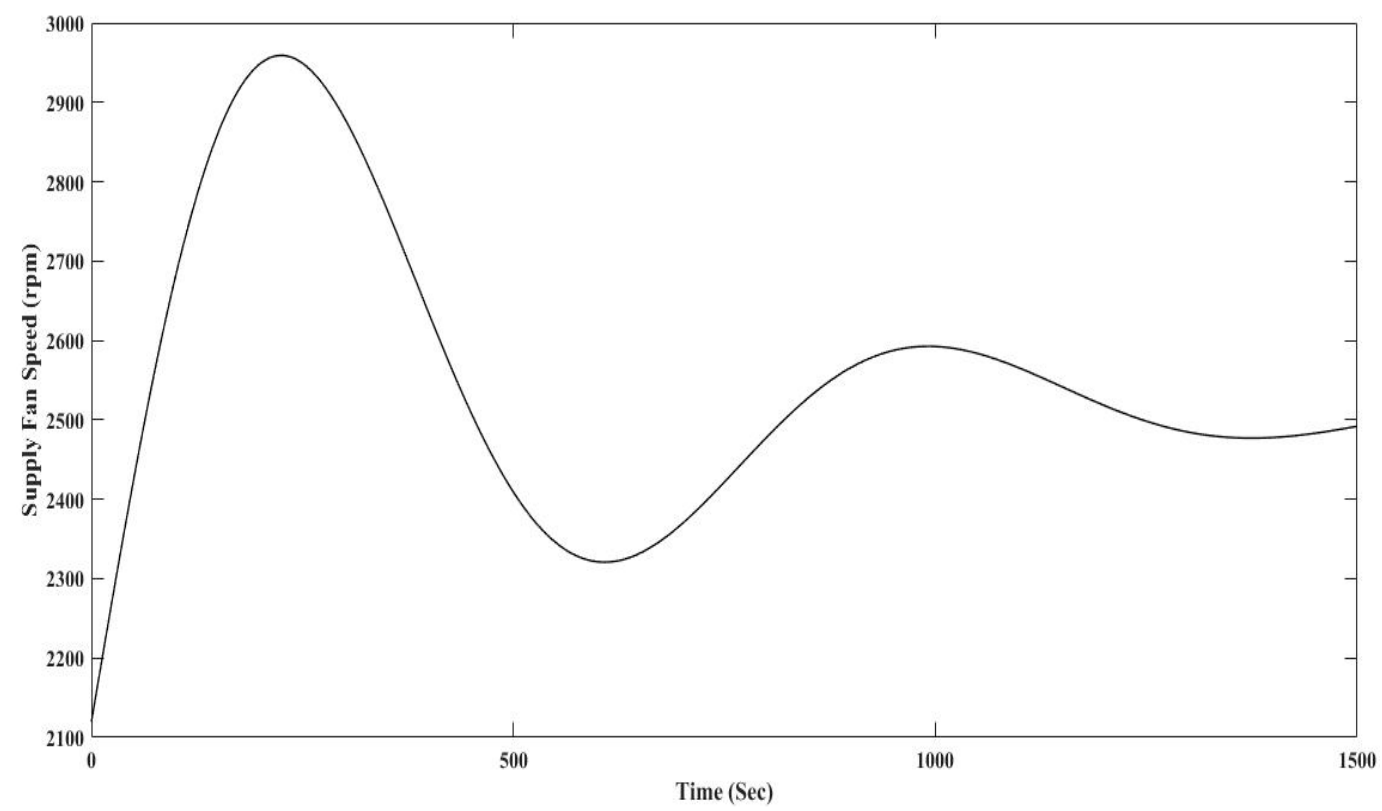

Figure 28. The speed of supply fan by LQG controller. 
Figure 29 shows the speed of the compressor. To decrease the temperature of the air conditioned room, the compressor speed increased from $3960 \mathrm{rpm}$ to $3960.42 \mathrm{rpm}$ in $223 \mathrm{~s}$, then by declining the air conditioned room temperature to the desired value, the speed of compressor decreased to $3960.1 \mathrm{rpm}$ at $609 \mathrm{~s}$ and finally reached to $3960.2 \mathrm{rpm}$ at $1197 \mathrm{~s}$ and maintained to keep the air conditioned room temperature and humidity in desired set points.

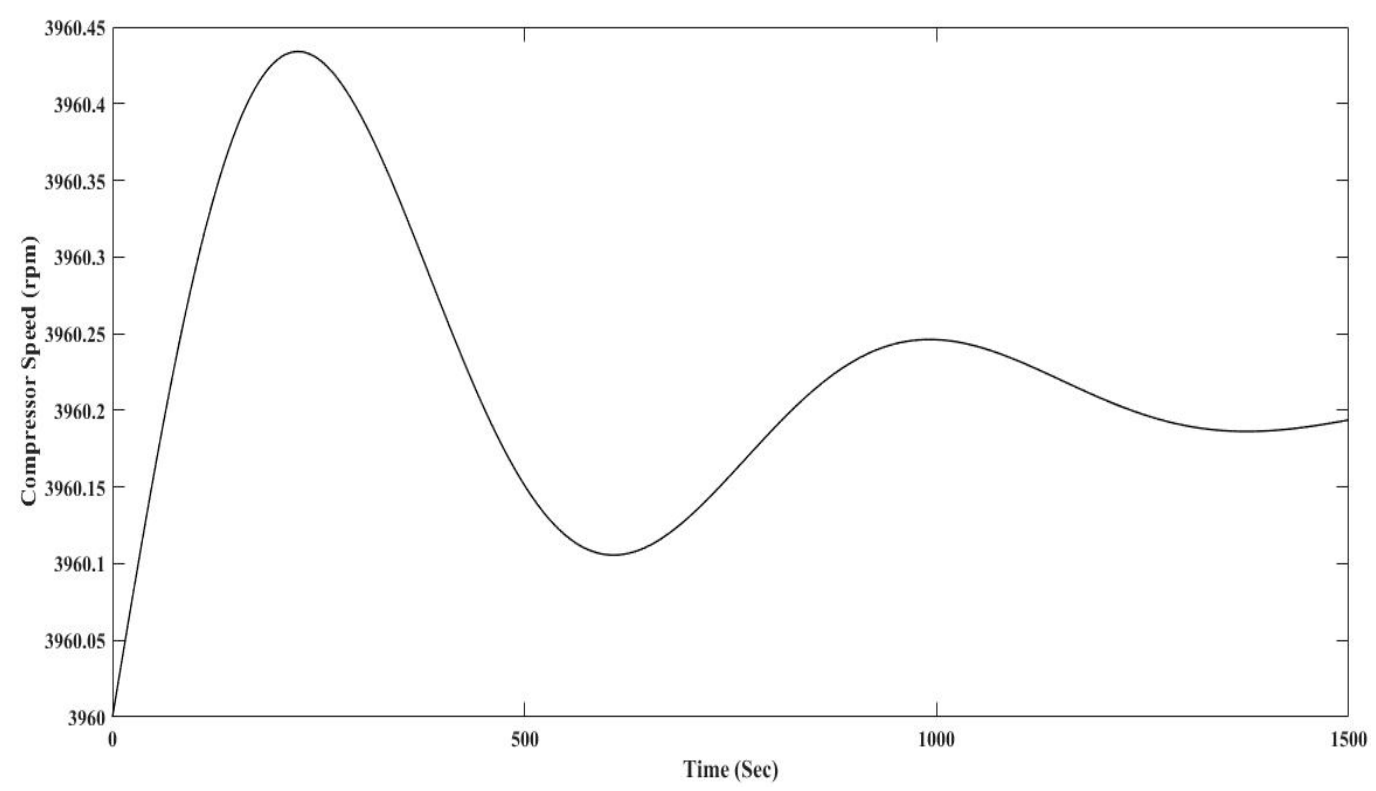

Figure 29. The speed of compressor by LQG controller.

In $1500 \mathrm{~s}$, the energy usage by compressor is $5.94 \times 10^{6}(\mathrm{~W})$ and the energy usage by supply fan is $3.828 \times 10^{6}(\mathrm{~W})$. The total energy usage by applying LQG controller is $9.768 \times 10^{6}(\mathrm{~W})$. It is clear that compared to the LQG controller, there is $0.216 \times 10^{6}(\mathrm{~W})$ reduction in energy usage in $1500 \mathrm{~s}$ runtime of the system by applying the GPC-FCM controller. This can be translated into a huge amount of energy savings per year.

In order to compare the performance of both controllers, the performances of the GPC-FCM controller and LQG controller which are applied on the same DX A/C system are compared under the same non-linear conditions by the ISE, IAE, and ITAE performance indexes [40-42]. The results are summarized in Table 3.

- Integral Square Error (ISE)

$$
I S E=\int(y(t)-r(t))^{2} d t
$$

- Integral of the absolute magnitude of error $(I A E)$

$$
I A E=\int|y(t)-r(t)| d t
$$

- Integral Time-absolute error (ITAE)

$$
I T A E=\int t|y(t)-r(t)| d t
$$


Table 3. Comparison the performance indexes of GPC-FCM control method and LQG control method based on temperature error and humidity error in $1500 \mathrm{~s}$ runtime.

\begin{tabular}{|c|c|c|c|c|}
\hline \multirow{3}{*}{$\begin{array}{l}\text { Performance } \\
\text { Index }\end{array}$} & \multicolumn{4}{|c|}{ Controller } \\
\hline & \multicolumn{2}{|c|}{ GPC-FCM } & \multicolumn{2}{|c|}{ LQG } \\
\hline & Temperature Error & Humidity Error & Temperature Error & Humidity Error \\
\hline ISE & 2857 & 0.05038 & $2.308 \times 10^{4}$ & 0.0602 \\
\hline$I A E$ & 1576 & 6.699 & 4096 & 7.719 \\
\hline ITAE & $8.217 \times 10^{5}$ & 2674 & $1.763 \times 10^{6}$ & 3457 \\
\hline
\end{tabular}

The parameter $y(t)$ is the measured control output and $r(t)$ is the desired set point value and $t$ is time.

According to the performance indexes results, it is clear that the GPC-FCM controller is able to minimize the performance indexes more than the LQG controller. In other words, the GPC-FCM controller is working better than the LQG controller under the same room conditions. This means that the GPC-FCM controller is more appropriate and applicable in comparison with the previous work on the same system.

\section{Discussion}

The controller can be structured based on the requisite scenario for the system of non-linear MIMO because the FCM method is established by actions, events, aims, tendencies and values of the system [29]. As the FCM structure is grounded by a graph structure with goals or tendencies of the system and simple mathematics, the controller's design in not involved with the system complexity and analysis of complex mathematics for extracting the control law. It can be easily applied to the system with nonlinear dynamic model. A hybrid non-linear MIMO control method on a nonlinear MIMO system is attained by using GPC-FCM controller which is an intelligent and soft control method. The advantages of improving the system by means of a novel control design on the non-linear MIMO system of DX A/C system with cross coupling effect are as follows:

- Excluding tough and complex mathematical analysis in the controller's design

- Structuring the controller within a vast operating range

- Simplifying the design of the nonlinear control via removing the observer

- Higher energy efficiency and lower energy consumption by applying the GPC method to decrease the usage of the energy by actuators.

The mentioned new control design indicates that the FCM method can suggest an easy solution when it encounters complicated problems. Abundant accurate and faster results can be achieved by this control platform to achieve an effective system performance, while avoiding wasting time in system mathematical modelling and finding the function of the Lyapunov for non-linear controller design. People who are unfamiliar with the system can apply the FCM method simply. The FCM is a more effective method to show the system using graphs with the casual relationships between states-concepts, especially for systems where the complete system is tremendously complicated or in some occasions, when is not possible by an accurate mathematical model. The symbolic method of control can be regarded as intelligent since it is simply adaptable and submissive to human subject knowledge and experience. Therefore, employing the FCM method as a control system can contribute to the improvement and expansion of more intelligent and autonomous systems. Last but not least, the FCM method has some features, such as a simple algorithm, good robustness and a small number of iteration steps which make it appropriate for real-time control of complex non-linear industrial processes. The comparison between the GPC-FCM control method and previous control methods are explained in Table 4. 
Table 4. Comparison between the proposed control method and previous control methods.

\begin{tabular}{|c|c|c|}
\hline Control Method & Advantages & Disadvantages \\
\hline Feedback linearization & $\begin{array}{l}\text { Quicker time responses from humidity and } \\
\text { temperature ratio in tracking objectives. } \\
\text { There is no obligation to know } \\
\text { the nonlinearity. } \\
\text { - Simultaneously, the disturbances in the } \\
\text { inner loop are decreased. }\end{array}$ & $\begin{array}{l}\text { - Increasing number of overshoots in } \\
\text { the outcomes. } \\
\text { Extra measurement is required. } \\
\text { The scale of time differences between } \\
\text { the inner and outer loop has to be } \\
\text { adequate enough (outer loop must be } \\
\text { slower than inner loop). }\end{array}$ \\
\hline Gain Scheduling & $\begin{array}{l}\text { - It is essential to identify the linear reigns } \\
\text { and switching logic design between } \\
\text { the regions. } \\
\text { In the mentioned regions, the tuning of } \\
\text { multiple PID controllers manually can be } \\
\text { completely complicated. } \\
\text { - Linear Techniques can be applied. } \\
\text { For specific scheduler variables, } \\
\text { the method can be identified as a feed } \\
\text { forward control. } \\
\text { Usually a limited number of different } \\
\text { control parameter values is adequate. }\end{array}$ & $\begin{array}{l}\text { - Certain professional attempts } \\
\text { required in identifying the } \\
\text { dependency between schedule } \\
\text { variable and values of parameter. } \\
\text { - Slow variations of the operating point } \\
\text { results in nonlinear behaviour of the } \\
\text { controlled system. } \\
\text { Stability proof could lead to } \\
\text { a problem. }\end{array}$ \\
\hline Back-stepping & - Optimal energy usage. & $\begin{array}{l}\text { - } \quad \text { Problem in identifying } \\
\text { a Lyapunov function. } \\
\text { - } \quad \text { Measuring all state variables. } \\
\text { A nonlinear observer demanded, } \\
\text { otherwise, all the state variables must } \\
\text { be measured. } \\
\text { - Having sensitivity to variation } \\
\text { of parameter. }\end{array}$ \\
\hline LQG & $\begin{array}{l}\text { - } \\
\text { and energy savings. } \\
\text { - } \\
\text { - } \\
\text { Enhancing Energy saving [43] } \\
\text { - } \\
\text { Fast response [43] }\end{array}$ & $\begin{array}{l}\text { The method employed on the system } \\
\text { linear model and it is feasible only for } \\
\text { a certain operating point. } \\
\text { The method is basically complicated. } \\
\text { Consequently, the assessment and } \\
\text { online operation of the optimal } \\
\text { feedback control indicates } \\
\text { a daunting problem. } \\
\text { It is required to have the model } \\
\text { of system. } \\
\text { Finding a proper model for the } \\
\text { system is needed [43]. }\end{array}$ \\
\hline
\end{tabular}

- $\quad$ Skipping complicated and complex mathematical analysis in controller design.

- Designing the controller in an extended operating variation.

- $\quad$ Removing the observer to simplify the design of nonlinear control

- Elimination of the decoupling to increase the sensitivity and precision of the system. energy consumption and enhance energy efficiency to reduce the consumption of the energy by actuators.

- The controller is completely sensitive to the preliminary state and to the sort of chosen concepts applied in the model of FCM.

- This method is not compatible with the classic fuzzy.

- $\quad$ Through the adaptability and flexibility of the FCM method, undershoot and overshoot can be eliminated.

- Applying one control scenario for embracing characteristics of the system. 


\section{Conclusions}

In sum, the controller is competent to work properly on a non-linear MIMO complex DX A/C system according to the attained results via employing the GPC-FCM controller on the DX A/C system. In addition, the outcomes demonstrate that the controller has the potential to control the conditions and maintain the system stability under disturbance conditions. At the satisfactory boundary of thermal comfort in humid and hot regions, the controller rejects the disturbances and maintains the humidity and temperature successfully. Moreover, the controller is capable of following the changing of set points during functioning and follow the new set points. The outcomes of the proposed nonlinear controller indicates the effectiveness of the proposed controller for energy saving and efficiency reasons. A hybrid non-linear MIMO control method for a non-linear MIMO system is achieved by means of applying the GPC-FCM controller as an intelligent and soft control method. Reduced energy usage of the air-conditioning system is achieved by applying a variable speed compressor and variable speed supply fan as well as employing the hybrid GPC-FCM control design for avoiding energy losses by making the errors of the controller as negligible as possible for non-linear conditions. This study proposes a new hybrid, MIMO, non-linear, intelligent, and robust controller which can be considered as a new development in the field of MIMO and non-linear feedback controllers. Although the system shows high complexity and non-linearity, the proposed controller is able to provide suitable control signals for applying to the plant by extracting a set of simplified laws. Some research directions which can be considered as a continuation of this study are the use of the Recursive Mean Square (RMS) or Least Mean Square (LMS) algorithms with the mentioned method to optimize the weights of the proposed controller to make the results smoother and faster.

Acknowledgments: The study was supported by the Universiti Putra Malaysia to publish in open access. I would like to thank Hossein Eliasi for his guidance in this research and Uranus Saadat for language editing of the manuscript.

Author Contributions: Farinaz Behrooz designed and developed the main parts of the research work, including designing the controller, simulation model, Performance analysis tests and analyses of the obtained results. Farinaz Behrooz was also mainly responsible for preparing the paper. Norman Mariun and Mohd Amran Mohd Radzi contributed in the simulation, analysis of the results, and writing parts of the paper. Abdul Rahman Ramli, and Mohammad Hamiruce Marhaban were involved in analysis of the results and actively contributed to finalize the manuscript.

Conflicts of Interest: The authors declare no conflict of interest.

\section{References}

1. Tashtoush, B.; Molhim, M.; Al-Rousan, M. Dynamic model of an HVAC system for control analysis. Energy 2005, 30, 1729-1745. [CrossRef]

2. Wang, J.; An, D.; Lou, C. Application of fuzzy-PID controller in heating ventilating and air-conditioning system. In Proceedings of the 2006 IEEE International Conference on Mechatronics and Automation, Luoyang, China, 25-28 June 2006; pp. 2217-2222.

3. Lei, J.; Hongli, L.; Cai, W. Model Predictive Control Based on Fuzzy Linearization Technique For HVAC Systems Temperature Control. In Proceedings of the 2006 1ST IEEE Conference on Industrial Electronics and Applications, Singapore, 24-26 May 2006; pp. 1-5.

4. Lu, L.; Wenjian, C.; Lihua, X.; Shujiang, L.; Yeng, C.S. HVAC system optimization-In-building section. Energy Build. 2005, 37, 11-22. [CrossRef]

5. Gruber, P.; Balemi, S. Overview of Non-Linear Control Methods; Technical Report; Swiss Society for Automatic Control: Switzerland, 2010.

6. Qi, Q.; Shiming, D. Multivariable control of indoor air temperature and humidity in a direct expansion (DX) air conditioning (AC) system. Build. Environ. 2009, 44, 1659-1667. [CrossRef]

7. Hongli, L.; Peiyong, D.; Qingmei, Y.; Hui, L.; Xiuwen, Y. A Novel Adaptive Energy-efficient Controller for the HVAC Systems. In Proceedings of the IEEE 2012 24th Chinese Control and Decision Conference (CCDC), Taiyuan, China, 23-25 May 2012; pp. 1402-1406. 
8. Qi, Q. Multivariable Control of Air Temperature and Humidity in a Space Served by Direct Expansion Air Conditioning System. Ph.D. Thesis, Polytechnic University Hong Kong, Hong Kong, China, 2009.

9. Dong, B. Non-Linear Optimal Controller Design for Building HVAC Systems. In Proceedings of the IEEE Multi-Conference on Systems and Control, Yokohama, Japan, 8-10 September 2010.

10. Xu, M.; Li, S.; Cai, W.; Lu, L. Effects of a GPC-PID control strategy with hierarchical structure for a cooling coil unit. Energy Convers. Manag. 2006, 47, 132-145. [CrossRef]

11. Xu, M.; Li, S. Practical generalized predictive control with decentralized identification approach to HVAC systems. Energy Convers. Manag. 2007, 48, 292-299. [CrossRef]

12. Ferhatbegovi'c, T.; Palensky, P.; Fontanella, G.; Basciotti, D. Modelling and design of a linear predictive controller for a solar powered HVAC system. In Proceedings of the IEEE International Symposium on Industrial Electronics (ISIE2012), Hangzhou, China, 28-31 May 2012; pp. 869-874.

13. Qi, Q.; Shiming, D. Multivariable control-oriented modelling of a direct expansion (DX) air conditioning (A/C) system. Int. J. Refrig. 2008, 31, 841-849. [CrossRef]

14. Chen, W. Modeling and Control of a Direct Expansion (DX) Variable-Air-Volume (VAV) Air Conditioning System. Ph.D. Thesis, Department of Building Services Engineering, Hong Kong Polytechnic University, Hong Kong, China, 2005.

15. Chen, W.; Deng, S. Development of a dynamic model for a DX VAV air conditioning system. Energy Convers. Manag. 2006, 47, 2900-2924. [CrossRef]

16. Shiming, D. The application of feedforward control in a direct expansion (DX) air conditioning plant. Build. Environ. 2002, 37, 35-40.

17. Shiming, D. A dynamic mathematical model of a direct expansion (DX) water-cooled air-conditioning plant. Build. Environ. 2000, 35, 603-613. [CrossRef]

18. Qi, Q.; Deng, S.; Xu, X.; Chan, M. Improving degree of superheat control in a direct expansion (DX) air conditioning (A/C) system. Int. J. Refrig. 2010, 33, 125-134. [CrossRef]

19. Cleland, A.C. Computer subroutines for rapid evaluation of refrigerant thermodynamics properties. Int. J. Refrig. 1986, 9, 346-351. [CrossRef]

20. Kim, M.; Kim, C.; Hong, S.; Kwon, I. Forward-backward analysis of RFID-enabled supply chain using fuzzy cognitive map and genetic algorithm. Expert Syst. Appl. 2008, 35, 1166-1176. [CrossRef]

21. Bertolini, M. Assessment of human reliability factors: A fuzzy cognitive maps approach. Int. J. Ind. Ergon. 2007, 37, 405-413. [CrossRef]

22. Lü, H.; Jia, L.; Kong, S.; Zhang, Z. Predictive functional control based on fuzzy T-S model for HVAC systems temperature control. J. Control Theory Appl. 2007, 5, 94-98. [CrossRef]

23. Papageorgiou, E.; Stylios, C.; Groumpos, P. Unsupervised learning techniques for fine-tuning fuzzy cognitive map causal links. Int. J. Hum.-Comput. Stud. 2006, 64, 727-743. [CrossRef]

24. Behrooz, F.; Mariun, N.; Marhaban, M.H.; Mohd Radzi, M.A.; Ramli, A.R. New design approach to MIMO nonlinear controller for direct expansion air conditioning system in building automation system. In Proceedings of the 2015 IEEE 15th International Conference on, Environment and Electrical Engineering (EEEIC), Rome, Italy, 10-13 June 2015; pp. 1706-1712.

25. Rossiter, A. Generalised Predictive Control, Videos on model predictive control. In University of Sheffield: Department of Automatic Control and Systems Engineering; University of Sheffield: Sheffield, UK, 2014; Chapter 2.

26. Kosko, B. Fuzzy cognitive maps. Int. J. Man Mach. Stud. 1986, 24, 65-75. [CrossRef]

27. Aguilar, J. A survey about fuzzy cognitive maps papers (Invited paper). Int. J. Comput. Cogn. 2005, 3, 27.

28. Khor, S.; Khan, M. Scenario Planning Using Fuzzy Cognitive Maps. In Proceedings of the 8th Australian and New Zealand Intelligent Information Systems Conference (ANZIIS2003), Sydney, Australia, 10-12 December 2003; pp. 311-316.

29. Stylios, C.; Groumpos, P. Fuzzy cognitive maps in modeling supervisory control systems. J. Intell. Fuzzy Syst. 2000, 8, 83-98.

30. Stylios, C.; Groumpos, P. Modeling complex systems using fuzzy cognitive maps. IEEE Trans. Syst. Man Cybern. Part A 2004, 34, 155-162. [CrossRef]

31. Papageorgiou, E.; Stylios, C.; Groumpos, P. Active Hebbian learning algorithm to train fuzzy cognitive maps. Int. J. Approx. Reason. 2004, 37, 219-249. [CrossRef] 
32. Behrooz, F.; Ramli, A.R.; Samsudin, K. A survey on applying different control methods approach in building automation systems to obtain more energy efficiency. Int. J. Phys. Sci. 2011, 6, 2308-2314.

33. Behrooz, F.; Ramli, A.R.; Samsudin, K.; Eliasi, H. Energy saving by applying the fuzzy cognitive map control in controlling the temperature and humidity of room. Int. J. Phys. Sci. 2017, 12, 13-23.

34. Martchenko, A.S.; Ermolov, I.L.; Groumpos, P.P.; Poduraev, J.V.; Stylios, C.D. Investigating Stability Analysis Issues for Fuzzy Cognitive Maps. In Proceedings of the 11th Mediterranean Conference on Control and Automation (MED'03), Rhodes, Greece, 18-20 June 2003.

35. Cheng, Q.; Fan, Z.T. The stability problem for fuzzy bidirectional associative memories. Fuzzy Sets Syst. 2002, 132, 83-90. [CrossRef]

36. American Society of Heating, Refrigerating, and Air-Conditioning Engineers (ASHRAE). Thermal Environmental Conditions for Human Occupancy, Standard 55; American Society of Heating, Refrigerating, and Air-Conditioning Engineers (ASHRAE): Atlanta, GA, USA, 1992.

37. Kwong, Q.J.; Adam, N.M.; Sahari, B.B. Thermal comfort assessment and potential for energy efficiency enhancement in modern tropical buildings: A review. Energy Build. 2014, 68, 547-557. [CrossRef]

38. Wafi, S.; Ismail, M.R. The relationship between thermal performance, thermal comfort and occupants. A study of thermal indoor environment in selected students accommodation in Universiti Sains Malaysia (USM). In Proceedings of the 2nd International Conference on Built Environment in Developing Countries (ICBEDC 2008), Penang, Malaysia, 3-4 December 2008; pp. 675-690.

39. Daghigh, R. Assessing the thermal comfort and ventilation in Malaysia and the surrounding regions. Renew. Sustain. Energy Rev. 2015, 48, 681-691. [CrossRef]

40. Balcerzak, M.; Dabrowski, A.; Kapitaniak, T.; Jach, A. Optimization of the Control System Parameters with Use of the New Simple Method of the Largest Lyapunov Exponent Estimation. Mech. Mech. Eng. 2013, 17, 225-239.

41. Mishra, C.K.; Jebakumar, J.S.; Mishra, B.K. Controller Selection and Sensitivity Check on the Basis of Performance Index Calculation. Int. J. Electr. Electron. Data Commun. 2014, 2, 91-93.

42. Li, Y.; O'Neill, Z.; Niu, F. Evaluating Control Performance on Building HVAC Controllers. In Proceedings of the 14th Conference of International Building Performance Simulation Association (BS2015), Hyderabad, India, 7-9 December 2015; pp. 464-471.

43. Perera, D.W. U.; Pfeiffer, C.F.; Skeie, N.O. Control of temperature and energy consumption in building-A review. Int. J. Energy Environ. 2014, 5, 471-484. 